Cooperative Research Units

Prepared in cooperation with U.S. Army Corps of Engineers

\title{
American and Sacramento Rivers, California, Erodibility Measurements and Model
}

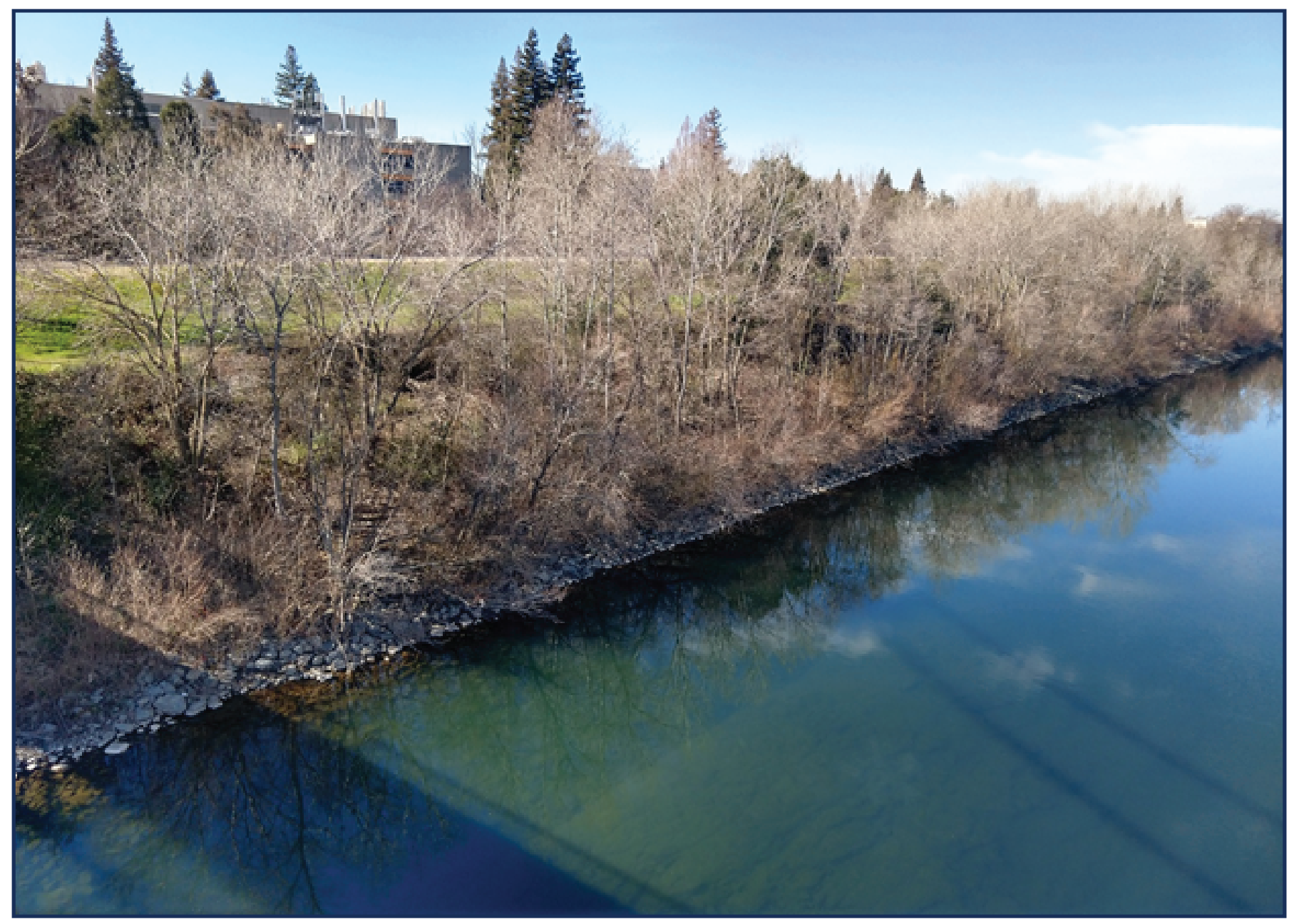

Scientific Investigations Report 2021-5052 
Cover photo: Left bank of the lower American River, looking downstream from the Guy West Bridge, Sacramento, California, on February 5, 2020. Photograph by Paul Work, U.S. Geological Survey. 


\section{American and Sacramento Rivers, California, Erodibility Measurements and Model}

By Paul Work and Daniel Livsey

Cooperative Research Units

Prepared in cooperation with U.S. Army Corps of Engineers

Scientific Investigations Report 2021-5052 


\section{U.S. Geological Survey, Reston, Virginia: 2021}

For more information on the USGS - the Federal source for science about the Earth, its natural and living resources, natural hazards, and the environment—visit https://www.usgs.gov or call 1-888-ASK-USGS.

For an overview of USGS information products, including maps, imagery, and publications, visit https://store.usgs.gov/.

Any use of trade, firm, or product names is for descriptive purposes only and does not imply endorsement by the U.S. Government.

Although this information product, for the most part, is in the public domain, it also may contain copyrighted materials as noted in the text. Permission to reproduce copyrighted items must be secured from the copyright owner.

Suggested citation:

Work, P., and Livsey, D., 2021, American and Sacramento Rivers, California, erodibility measurements and model: U.S. Geological Survey Scientific Investigations Report 2021-5052, 30 p., https://doi.org/10.3133/sir20215052.

Associated data for this publication:

Work, P.A., and Livsey, D., 2021, Borehole Erosion Test data, Lower American and Sacramento Rivers, California, 2019 (ver. 4.0, 2021), https://doi.org/10.5066/P96MCT20.

ISSN 2328-0328 (online) 


\section{Acknowledgments}

The authors would like to acknowledge financial support from the U.S. Army Corps of Engineers (USACE) and acknowledge the contributions of the following individuals to the work presented in this report: Jonathan AuBuchon, Richard Harvey, Patricia Cason, Chi Bui, and Todd Rivas of USACE; Eddy Langendoen and Michael Ursic of the U.S. Department of Agriculture; and JeanLouis Briaud, Anna Shidlovskaya, and Anna Timchenko of Texas A\&M University. 



\section{Contents}

Acknowledgments …........................................................................................................................

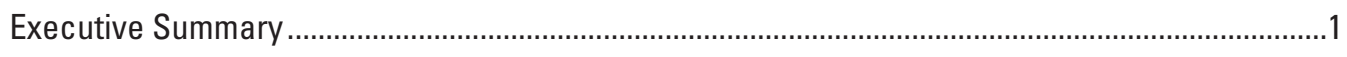

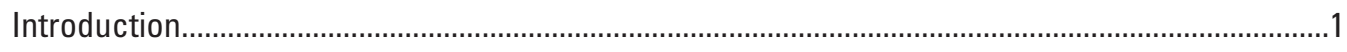

Comparison of the Three Methods for Quantifying Erodibility .......................................................

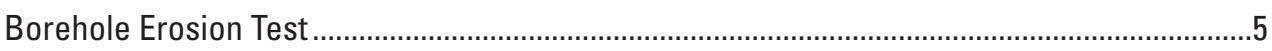

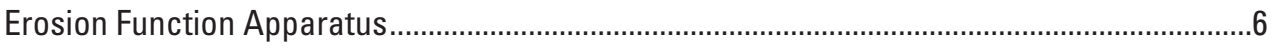

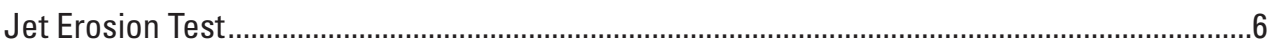

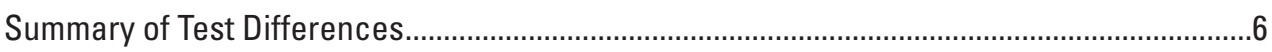

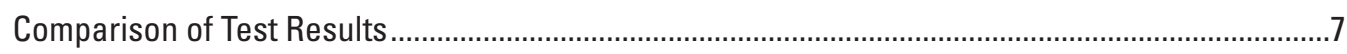

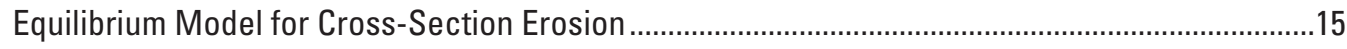

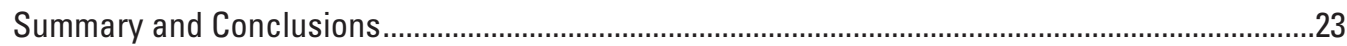

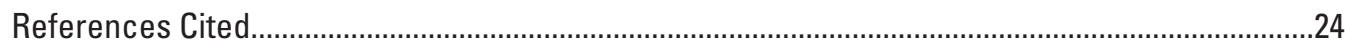

Appendix 1. Plots Relating Erosion and Shear Stress Data Derived from Borehole Erosion Tests for the Americ an and Sacramento Rivers.....................................................26

\section{Figures}

1. Map showing test sites along the American River, California ...........................................

2. Map showing test sites along the Sacramento River, California .......................................

3. Graph showing borehole erosion test results showing relations between erosion rate and shear stress for three lithological layers at site LAR2 on the lower American River, California ...

4. Graph showing erosion rate by shear stress plotted for all layers and sites considered in the borehole erosion test dataset for the American and Sacramento Rivers

5. Graph showing erosion coefficient $k$ estimated from erosion function apparatus test results and reported by Briaud and others (2020) compared to values derived from borehole erosion test results by the authors for the American and Sacramento Rivers

6. Graph showing critical shear stresses from jet erosion tests reported by Langendoen and Ursic (2020) for the American and Sacramento Rivers, California .......13

7. Graph showing critical shear stresses reported by Briaud and others (2020) for borehole erosion tests and erosion function apparatus tests for the American and Sacramento Rivers, California

8. Graph showing erosion coefficients $k$ derived from jet erosion test results, reported by Langendoen and Ursic (2020) for the American and Sacramento Rivers, California

9. Graph showing estimates of erosion coefficient $k$ derived from erosion function apparatus tests and reported by Briaud and others (2020) for the American and Sacramento Rivers, California.....

10. Graph showing cross section at station LAR4 on the American River, California, as viewed looking downstream.

11. HEC-RAS plot showing cross section at station LAR4 on the American River, California, and the division of the channel cross section into left, center, and right computational zones, with each zone having one flow speed. 
12. Hydrograph showing simulated peak-flow event period on the lower American River, California, in HEC-RAS model

13. Graph showing simulation of erosion response to a 200-year peak-flow event at station LAR4 on the lower American River, California..

14. Graph showing model results of erosion caused by a simulated 200-year peak-flow event at station LAR4, lower American River, California

15. Photograph showing view of the left bank of the lower American River, looking downstream from the Guy West Bridge, Sacramento, California, on February 5, 2020

16. Graph showing sensitivity of equilibrium cross section for 200-year peak-flow event at station SAC3 on the Sacramento River, California, to specified critical shear stress

17. Graph showing sensitivity of erosion to bed-drag coefficient. 22

\section{Tables}

1. Approximate locations and depths for drilling sites on the Lower American River, California

2. Approximate locations, elevations, and hole depths for drilling sites on the Sacramento River, California

3. Critical shear stresses at station LAR8 on the American River, California, as reported by Langendoen and Ursic (2020).

4. Erosion model parameters and initial values of bed shear stress

5. Model results showing changes in cross-sectional areas caused by erosion from a 200-year peak-flow event at selected locations on the lower American and Sacramento Rivers, California

\section{Conversion Factors}

International System of Units to U.S. customary units

\begin{tabular}{lll}
\hline \multicolumn{1}{c}{ Multiply } & \multicolumn{1}{c}{ By } & \multicolumn{1}{c}{ To obtain } \\
\hline centimeter $(\mathrm{cm})$ & \multicolumn{1}{c}{ Length } & \\
millimeter $(\mathrm{mm})$ & 0.3937 & inch (in.) \\
meter $(\mathrm{m})$ & 0.03937 & inch (in.) \\
kilometer $(\mathrm{km})$ & 3.281 & foot (ft) \\
meter $(\mathrm{m})$ & 0.6214 & mile (mi) \\
& 1.094 & yard (yd) \\
\hline square meter $\left(\mathrm{m}^{2}\right)$ & \multicolumn{1}{c}{ Area } & \\
square kilometer $\left(\mathrm{km}^{2}\right)$ & 0.0002471 & acre \\
square centimeter $\left(\mathrm{cm}^{2}\right)$ & 247.1 & acre \\
square meter $\left(\mathrm{m}^{2}\right)$ & 0.001076 & square foot $\left(\mathrm{ft}^{2}\right)$ \\
hectare (ha) & 10.76 & square foot $\left(\mathrm{ft}^{2}\right)$ \\
square kilometer $\left(\mathrm{km}^{2}\right)$ & 0.003861 & square mile $\left(\mathrm{mi}^{2}\right)$ \\
\hline
\end{tabular}




\begin{tabular}{|c|c|c|}
\hline Multiply & By & To obtain \\
\hline \multicolumn{3}{|c|}{ Volume } \\
\hline cubic meter $\left(\mathrm{m}^{3}\right)$ & 35.31 & cubic foot $\left(\mathrm{ft}^{3}\right)$ \\
\hline cubic meter $\left(\mathrm{m}^{3}\right)$ & 1.308 & cubic yard $\left(\mathrm{yd}^{3}\right)$ \\
\hline \multicolumn{3}{|c|}{ Speed and flow rate } \\
\hline meter per second $(\mathrm{m} / \mathrm{s})$ & 3.281 & foot per second $(\mathrm{ft} / \mathrm{s})$ \\
\hline cubic meter per second $\left(\mathrm{m}^{3} / \mathrm{s}\right)$ & 35.31 & cubic foot per second $\left(\mathrm{ft}^{3} / \mathrm{s}\right)$ \\
\hline \multicolumn{3}{|c|}{ Mass to weight } \\
\hline gram (g) & 0.03527 & ounce, avoirdupois (oz) \\
\hline kilogram (kg) & 2.205 & pound avoirdupois (lb) \\
\hline metric ton $(\mathrm{t})$ & 1.102 & ton, short $[2,000 \mathrm{lb}]$ \\
\hline metric ton $(\mathrm{t})$ & 0.9842 & ton, long $[2,240 \mathrm{lb}]$ \\
\hline \multicolumn{3}{|c|}{ Pressure } \\
\hline kilopascal (kPa) & 20.88 & pound per square foot $\left(\mathrm{lb} / \mathrm{ft}^{2}\right)$ \\
\hline kilopascal (kPa) & 0.1450 & pound per square inch $\left(\mathrm{lb} / \mathrm{ft}^{2}\right)$ \\
\hline
\end{tabular}

\section{Datum}

Vertical coordinate information is referenced to the North American Vertical Datum of 1988 (NAVD 88).

Horizontal coordinate information is referenced to the North American Datum of 1983 (NAD 83).

Elevation, as used in this report, refers to distance above the vertical datum.

\section{Abbreviations}

$\begin{array}{ll}\text { ARS } & \text { Agricultural Research Service } \\ \text { BET } & \text { borehole erosion test } \\ \text { BSTEM } & \text { Bank Stability and Toe Erosion Model } \\ \text { EFA } & \text { erosion function apparatus } \\ \text { HEC-RAS } & \text { Hydrologic Engineering Center-River Analysis System } \\ \text { JET } & \text { jet erosion test } \\ \text { LAR } & \text { lower American River } \\ \text { SAC } & \text { Sacramento River } \\ \text { USACE } & \text { U.S. Army Corps of Engineers } \\ \text { USDA } & \text { U.S. Department of Agriculture } \\ \text { USGS } & \text { U.S. Geological Survey }\end{array}$





\title{
American and Sacramento Rivers, California, Erodibility Measurements and Model
}

\author{
By Paul Work and Daniel Livsey
}

\section{Executive Summary}

A previous report by the authors described sediment sampling and drilling by the U.S. Geological Survey (USGS) beside the American and Sacramento Rivers near Sacramento, California, in support of a U.S. Army Corps of Engineers project focused on regional flood control. The drilling was performed to define lithology, extract samples for laboratory testing, and perform borehole erosion tests (BETs). The U.S. Department of Agriculture (USDA) performed jet erodibility tests (JETs) near each drilling site, and a team from Texas A\&M University performed laboratory tests with an erosion function apparatus (EFA). Collectively, the effort was intended to reveal spatial variations in sediment erodibility and provide data for use in a model to simulate morphological response to a major flood. The data collected by the USGS are available in a public data release.

This report, developed in cooperation with the U.S. Army Corps of Engineers, provides comparisons of the three types of measurements of the erodibility of riverbed sediments. The BET is performed in the field and reveals erodibility of sediments below the bed surface. The JET is likewise performed in the field but reveals only erodibility of exposed sediments. The EFA test is done in the laboratory and was performed on soils extracted from different depths beneath the bed surface, in many cases reconstituted for laboratory testing. Tests were performed at nominally similar locations but differed by meters to tens of meters in horizontal locations.

The comparison was undertaken to investigate differences among results obtained by the individual measurement approaches and to elucidate pros and cons of each method. The critical shear stress to initiate erosion and the rate of change of erosion rate per unit increase of excess shear stress, sometimes referred to as the erosion coefficient, served as the primary basis for comparison. The three test methods in some cases resulted in order of magnitude differences in estimates of these parameters. Some differences could be attributed to variances in site location or result from testing surface sediment versus a deeper layer, but systematic differences are also evident in the results. The tests performed in the laboratory using the EFA resulted in much lower values of critical shear stress and much higher values of the erosion coefficient compared to the JET tests performed by the USDA team on surface sediments. Critical shear stress was poorly resolved in the BET results because of the limited number of results per site, but the erosion coefficients derived from BET results were systematically lower than those obtained using the EFA.

A new, simplified approach is also proposed to estimate the increase in channel cross-sectional area during a large flood, given data describing the initial river cross section, riverbed erodibility parameters, and peak flood discharge and duration. The model runs until the cross section erodes to an equilibrium condition or the flood ends. Output describes the area of the cross section at the end of the simulation and the time required to reach equilibrium if it was reached within the simulated period. The model assumes unique, constant values for both the critical shear stress and the erosion coefficient and represents the fluid mechanics in a simplified way, making it of limited value for quantitative predictions. It does, however, provide an indication of which cross sections are most likely to undergo the greatest change in the design event and can be used to investigate sensitivity of erosion predictions to variability in sediment erodibility measurements.

\section{Introduction}

Sacramento, California, is on a low floodplain near the confluence of the American and Sacramento Rivers in northern California (fig. 1). Despite protection provided by reservoirs and levees, flooding is a persistent concern, and an ongoing project led by the U.S. Army Corps of Engineers (USACE) includes efforts to assess and reduce the risk of infrastructure failures - particularly of levees - in major floods. Large floods have the potential to erode channel cross sections and thus threaten the integrity of levees that could fail by undermining, even if the levees are structurally sound. Estimation of the likelihood of this type of failure and optimization of plans for countermeasures require measurements of the erodibility of the soils between the levees, including sediments below grade, with the term "below grade" meaning beneath the sediment surface.

In the Sacramento region, USACE is relying on hydrodynamic simulations from the Hydrologic Engineering CenterRiver Analysis System (HEC-RAS) quasi-two-dimensional surface-water model (U.S. Army Corps of Engineers, 2016) 
coupled with the Bank Stability and Toe Erosion Model (BSTEM; Simon and others, 2000, 2011; Klavon and others, 2017) to assess the potential erosion during a peak-flow event in the study area. The approach taken in the Sacramento-area study involved dividing the channel laterally into three hydrodynamic zones, simulating the passage of a peak-flow event with a representative hydrograph, and estimating the potential for channel scour and for levee or bank failure.

All numerical models of unsteady processes require specification of initial and boundary conditions. For simulation of river hydrodynamics, the most fundamental inputs are initial channel geometry and roughness, water level, and discharge. To simulate the resulting erosion, it is necessary to know sediment properties, both along and below the riverbed surface, including critical flow speed or shear stress to initiate motion and the rate of erosion once the critical shear stress is exceeded. The term "riverbed" is used throughout this report to refer to the entire region between levees. During a design peak-flow event, this region is expected to be completely submerged and potentially subject to erosional stress due to flowing water. Often, the resulting sediment erosion rates are assumed to be proportional to some power of excess shear stress, defined as applied shear stress minus the critical shear stress to initiate motion (Yang, 1996; Van Prooijen and Winterwerp, 2010).

Critical velocity, shear stress, and sediment erodibility can be highly variable in both space and time. It is therefore desirable to obtain site-specific data defining these parameters.
A previous report by the authors (Work and Livsey, 2020) described the application of the borehole erosion test (BET; Briaud and others, 2017) to estimate sediment erodibility beneath the riverbed surface at 13 sites along the American and Sacramento Rivers (chosen from the sites shown in figures 1 and 2). In addition to the BET data collection, sediment cores were extracted to allow definition of sediment characteristics and properties relative to depth below grade and to obtain samples for laboratory testing at Texas A\&M University in an erosion function apparatus (EFA; Briaud and others, 2001, 2020). Other project team members from the U.S. Department of Agriculture's Agricultural Research Service (USDA-ARS) used a jet erosion test (JET) apparatus to make in situ observations of erodibility of surface sediments along the two rivers (Hanson and Cook, 2004; Simon and others, 2010; Langendoen and Ursic, 2020).

Many other methods have been developed and tested to quantify sediment erodibility in laboratory and field settings. Erodibility, like some other sediment properties or characteristics, is dependent not only on the composition of the sediment, but also on the packing and burial history of the particles in the sediment matrix. Disturbing the sediment by removing it can change the property that is being measured, but with careful extraction, it is possible to minimize the effects of these disturbances. Examples of erodibility tests done in the field or with extracted cores are provided by Hanson (1991), Maa and others (1993), McNeil and others (1996), Tolhurst and others (2000), Briaud and others (2001), Hanson and Simon (2001),

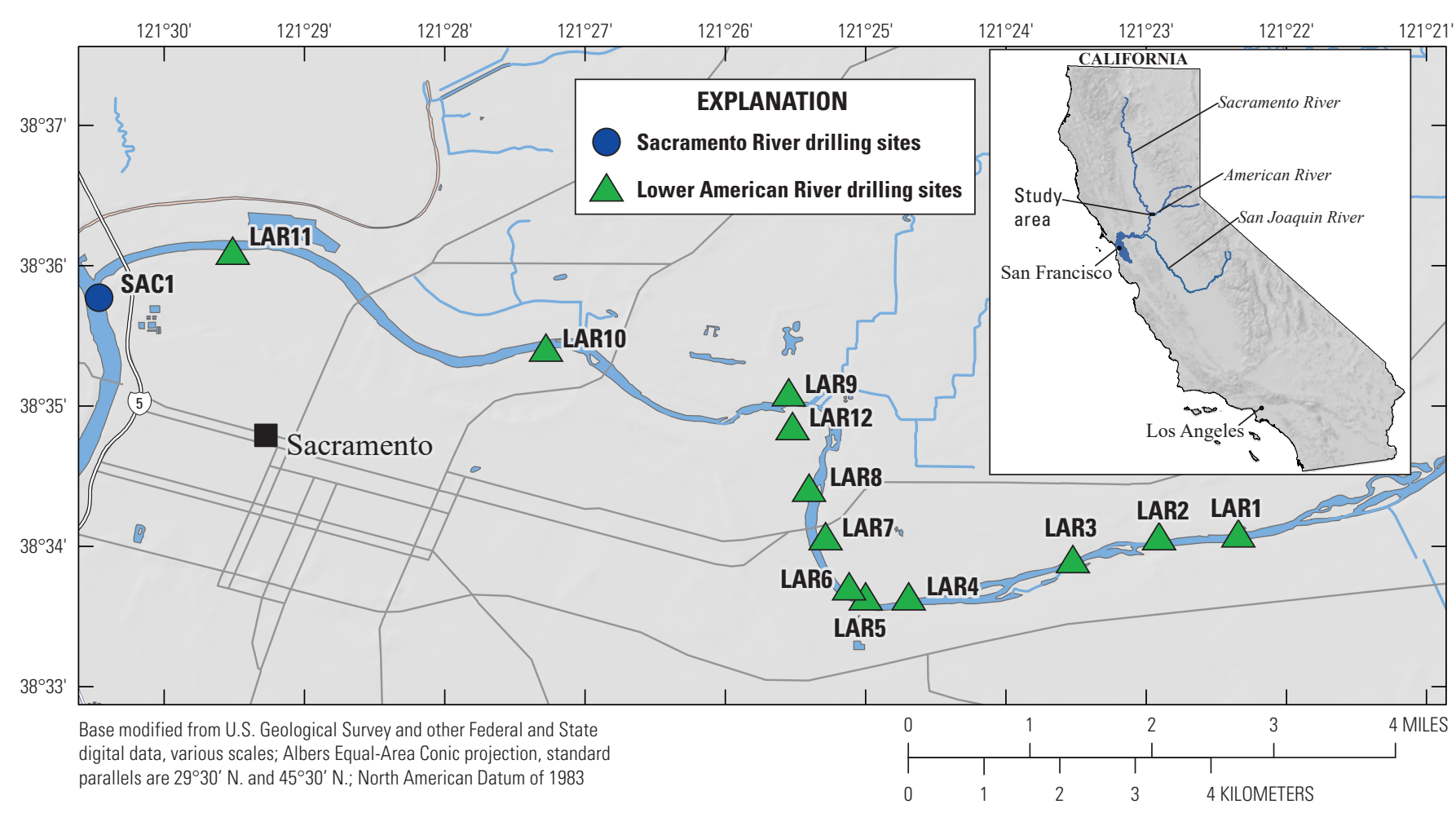

Figure 1. Test sites along the American River, California. Borehole erosion test (BET) sites featured two drilled holes: one to define lithology and provide samples for laboratory testing, and one for the BET. 


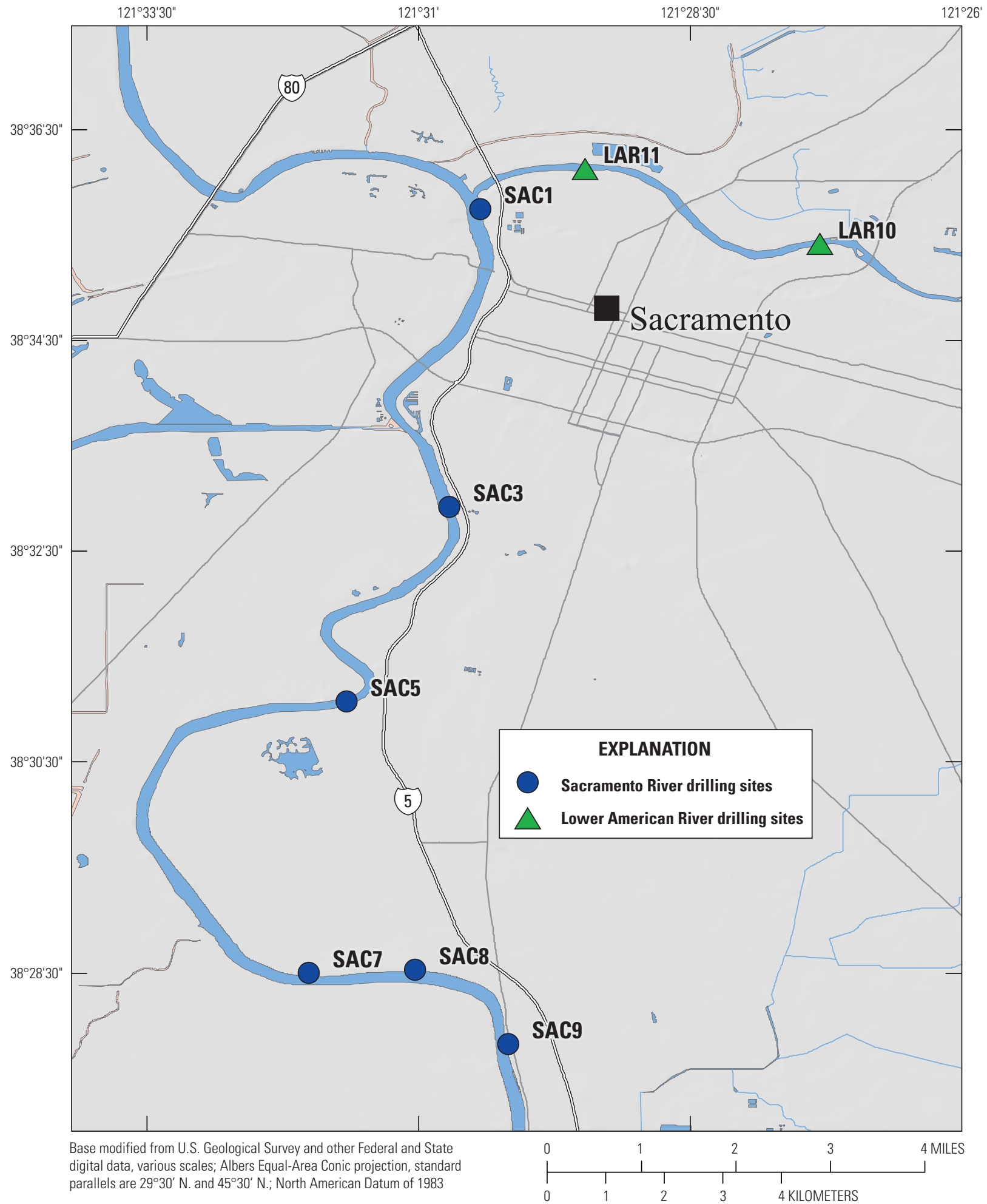

Figure 2. Test sites along the Sacramento River, California. Borehole erosion test (BET) sites featured two drilled holes: one to define lithology and provide samples for laboratory testing, and one for the BET. 
Roberts and others (2003), Hanson and Cook (2004), Trammel (2004), Borrowman and others (2006), Ravens (2007), Jones and Gailani (2009), Daly and others (2013), Khanal and others (2016), Work and Schoellhamer (2018), and Tran (2018). Because of the importance of sediment transport in ecological and engineering problems, a large body of related work is available for reference. The focus of this report is the methods used in the project that funded this report: the BET, the EFA, and the mini-jet erosion test (JET).

When drilling equipment is available, it is possible to extract samples at various depths below grade and to test extracted cores in the laboratory to create an erodibility profile. This is often done in a recirculating flume; see Briaud and others (2001), Trammel (2004), National Academies of Sciences, Engineering, and Medicine (2004), and Tran (2018) for examples. The EFA developed by Briaud and others (2001) uses a recirculating flume and is patented and marketed by Humboldt Manufacturing Company. Trammel (2004) reviews the EFA and other laboratory test options. Tran (2018) added photogrammetry and other improvements to the approach proposed by Briaud and others (2001).

Details of the BET work are provided in Work and Livsey (2020), and details of the companion EFA and JET testing are available in reports provided to USACE by Texas A\&M University (Briaud and others, 2020) and the USDA-ARS group (Langendoen and Ursic, 2020), respectively. The primary purpose of this report, developed in cooperation with the U.S. Army Corps of Engineers, is to compare the three sets of results and describe a model for ranking potential erodibility of river cross sections. All three types of measurements were done to reveal sediment erodibility, and each type has pros and cons (Tolhurst and others, 2000; Jepsen, 2006; Widdows and others, 2007). The project provided an unusual opportunity to compare all three types of measurements using data from one project region.

Erodibility data are used to constrain erosion parameters in "The Bank Stability and Erosion Model" (BSTEM; Simon and others, 2011) developed to simulate fluvial erosion and slope failures, such as can happen when the toe of a levee is eroded. BSTEM includes computation of flow-induced erosion that modifies bank profiles, and slope stability is then evaluated. Slope failure results in redistribution of material that can then be eroded, although the effect of this redistribution on the flow speeds in the river is not assessed. The influences of groundwater and vegetation on slope stability are incorporated. The BSTEM model has been linked with the HEC-RAS model to simulate quasi-two-dimensional flow and bank erosion in rivers. The Sacramento District office of the U.S. Army Corps of Engineers provided the U.S. Geological Survey with HEC-RAS model input and output for the American and Sacramento Rivers that were in turn used as input to the new model described in this report. At the time of publication of this report, no report was available describing the HEC-RAS results developed by the U.S. Army Corps of Engineers and utilized in this report.
As part of this report, a simplified model of an eroding river cross section was developed to simulate the flow-induced erosion of a river cross section. This was done primarily to see whether cross sections of interest should be expected to reach equilibrium during the design peak flow, which cross sections were likely to undergo the greatest change, and to reveal the sensitivity of predicted erosion to erodibility parameters inferred from the three different types of erodibility tests. By revealing which cross sections are most likely to substantially erode in the design peak flow, the results can serve as a check on results from the HEC-RAS and BSTEM simulations. The new model requires discharge, stage, and initial crosssectional geometry, and uses critical shear stress and erodibility coefficient (increase in erosion rate per unit increase in bed shear stress) from field or lab tests of sediment erodibility. The input parameters were taken from HEC-RAS model results provided by the Sacramento District of the U.S. Army Corps of Engineers. All input parameters are available in a USGS ScienceBase data release that accompanies this report (Work and Livsey, 2021). A new model for equilibrium river cross section is described and discussed in this report. This report is divided into the following major sections:

(1). This introduction and the executive summary that precedes it.

(2). Brief discussion of each of the three erodibility test methods, primarily focusing on pros and cons.

(a). Borehole erosion test (BET).

(b). Erosion function apparatus (EFA).

(c). Jet erosion tests (JET).

(3). Comparison of results from the three test approaches.

(4). Equilibrium model for river cross-section evolution.

(5). Conclusions.

(6). References.

(7). An appendix containing details of erodibility tests.

\section{Comparison of the Three Methods for Quantifying Erodibility}

A brief description of each test methodology for quantifying sediment erodibility is provided here in order to identify the pros and cons associated with each method. Data collection and test results for each approach are described in Work and Livsey (2020), Briaud and others (2020), and Langendoen and Ursic (2020). 


\section{Borehole Erosion Test}

The borehole erosion test (BET) requires the use of a drilling rig to create a small-diameter vertical hole to the depth of interest below grade. A drilling rod is inserted in the hole and water is pumped through the rod to create high speed flow within the annulus created between the rod and the earthen wall of the hole. The hole profile is measured before and after flow to quantify change, and the test is repeated for other flow speeds. The primary steps in the data collection process are as follows:

(1). Drill a hole to a specified depth below grade. This was done with a drilling bit attached to a rotating drilling rod through which water was pumped during drilling. The goal was to create a vertical hole with minimum diameter; 75 millimeters $(\mathrm{mm})$ diameter was typical. Experience showed that loose sands are problematic, and that it is prudent to stay above the water table to avoid collapses of the hole wall during and after drilling.

(2). Use a digital caliper to measure the profile of the hole before testing. The caliper used in this study featured three spring-loaded fingers and a diameter resolution of $2.5 \mathrm{~mm}$.

(3). Repeat the measurement of hole geometry at least once to allow averaging to reduce the influence of random errors and account for an out-of-round hole or voids.

(4). Reinsert the drilling rod and pump water through it for a known duration at a known discharge. Duration was typically 10 minutes to tens of minutes, based on experience.

(5). Measure the hole profile again, two or more times.

(6). Repeat the flow test for one or more different discharges, with caliper readings made before and after each. Experience showed that the largest discharge test should be done first.

More details about the data collection process can be found in Work and Livsey (2020). To process the data, diameter changes were computed for each part of the borehole, and a mean velocity magnitude (hereafter referred to simply as velocity) was computed for that test for that section of the hole. The diameter of the outside of the rod is denoted by $D_{p}$ and that of the hole as $D_{h}$. Together they define an annulus area, $A$ (eq. 1). With a constant discharge $(Q)$, the velocity $(V)$ can be related to the two diameters and the discharge as follows:

$$
Q=V A=V\left[\frac{\pi}{4}\left(D_{h}^{2}-D_{p}^{2}\right)\right]
$$

Because the hole diameter changes during the test, a measure of diameter or annulus area must be selected to use for this calculation. A large change in diameter helps reduce uncertainty in the computed erosion rate by improving the test's signal-to-noise ratio but results in more time dependence in the velocity during the test. In practice, the average of the before- and after-test values of the annulus area was used to determine a mean area, which in turn was used with equation 1 to determine mean velocity for a given location for each flow period. Erosion rate is defined as the change in radius for a given flow period divided by its duration.

With the BET approach, at any given location within the hole, an erosion rate and a velocity could be determined for each flow period. After performing several tests, many erosion rate-velocity pairs were available to define the relation between these two variables. Given suitable equations for friction factor and shear stress (discussed further below), an empirical relation between shear stress and erosion rate could be established. The resulting dataset describes the variation in erodibility over the entire hole, which can span multiple sediment layers or types. The major pros of the BET can be summarized as follows:

(1). The test can be done on site, without any need for further laboratory analysis.

(2). It is conceptually simple.

(3). It involves little in the way of consumables. In this case, water had to be hauled to and from the site, cuttings had to be disposed of, and grout had to be provided to seal holes.

(4). A single flow rate can provide many different erosion rate-velocity (or shear stress) data pairs if the hole erosion varies vertically, as was the case in every test performed for this project.

Work and Livsey (2020) reported some of the cons associated with the BET, including the following:

(1). It is labor- and equipment-intensive. The minimum workable crew in this case featured three drillers and two instrument operators who also served as note takers.

(2). Slumping within the hole appears as erosion. Experience revealed that it was prudent to drill shallow holes to stay above the water table to avoid slumping in the sandy sediments encountered in the study area. Drilling mud was tested as a solution for this problem, but drilling mud substantially modified behavior of the eroding sediment and invalidated the tests.

(3). When testing above the water table, the eroded sediment is not saturated in advance of the test, whereas eroded sediment would be saturated in a design peakflow event.

(4). Highly permeable sediments such as gravels can lead to water loss that is assumed negligible when computing flow velocity magnitude associated with the test. This also alters the degree of saturation of the sediments. 
(5). Measured discharges were in some cases highly variable in time during a test.

(6). Even without time dependence in discharge, velocity magnitude at a point varies during a test as the hole erodes, which introduces uncertainty into the relations between velocity or shear stress and erodibility.

(7). Unless a separate hole is drilled and samples are extracted, lithology is unknown, complicating interpretation of results. In this study, separate holes were drilled to define lithology and obtain sediment samples for laboratory testing.

(8). Data for high-velocity tests are difficult to obtain. It is best to do the highest flow rate first, when the annulus is small. As the hole gets larger, greater pumping capacities are required to achieve a given velocity.

(9). In practice, by the time three or four tests had been performed, the hole had often eroded to the point where further testing was not feasible because of pump limitations. Pumping capacity limited the amount of data available for interpretation. In particular, defining the velocity at which erosion was initiated was difficult.

(10). Some of the bored holes evolved into convoluted shapes, with abrupt changes in diameter throughout the depth of the hole. Tortuous borehole shapes complicate the estimation of the resulting flow and shear stresses applied to the sediment.

\section{Erosion Function Apparatus}

The EFA, like the BET, is also conceptually simple because it involves a small core within a Shelby tube that is pushed vertically upward into a channel through which water is flowing. The water speed at which erosion is initiated can be noted, and the erosion rate is defined by the speed at which the core must be pushed vertically upward to remain level with the floor of the channel. Discharge through the channel can be controlled to achieve any desired number of flow speeds.Pros of the EFA approach include the following:

(1). By using a sample collected in the field with a Shelby tube, the sample should be minimally disturbed and therefore representative of field conditions. In many cases in this study, however, sediments extracted in the field were bagged and reconstituted in the laboratory for testing.

(2). The tested section of sediment is small in vertical extent and less likely to span multiple sediment layers.

(3). The water flow within the test apparatus is less complex than in the borehole test and is represented better by the equations typically used to relate discharge, velocity, and shear stress.
(4). By gradually increasing the flow rate in the test apparatus, better definition of the point at which erosion is initiated is possible.

(5). An unlimited number of flow speeds can be used during the tests to improve the resolution of the curve describing relations between erodibility and shear stress.

(6). Because Shelby tubes can be obtained from any reachable depth, tests can provide definition of vertical variability in erodibility.

(7). The sample is submerged and subjected to horizontal flow during testing, as it would be in natural conditions.

Cons of the EFA test include:

(1). Labor-intensive drilling is needed to obtain the required samples.

(2). The test is not performed in situ; therefore, disturbances can potentially alter observed erosion rates.

(3). Specialized laboratory equipment is required.

(4). Resolution of results in the vertical is limited by sampling strategy.

\section{Jet Erosion Test}

The JET involves placing a cylinder on top of the sediment to be tested, filling the cylinder with water, shooting a downward jet of water through the filled cylinder, and documenting the erosion of the sediment beneath the jet with time. Pros of this approach include the following:

(1). The test is performed in situ.

(2). The equipment size is manageable; a drilling rig is not required.

(3). The hydrodynamic aspects of the experiment are controlled and can be varied through a wide range.

Cons include the following:

(1). Only surface sediments and sediments just below the surface are tested.

(2). The test involves a normally incident jet of water striking sediment, whereas the situation in nature involves a tangentially applied shear stress on the riverbed.

(3). There is no direct measurement of velocity magnitude or shear stress creating the observed erosion.

\section{Summary of Test Differences}

The BET and JET are both performed in the field, and the EFA test is done in the laboratory. The BET reveals vertical variability in erodibility within the scope of one test, the 
EFA requires many tests to reveal this variability, and the JET does not reveal vertical variability in erodibility. All three approaches have the potential to provide useful information, but they do so in different ways.

\section{Comparison of Test Results}

The different types of tests were not all done at the same locations or times. The samples that were analyzed by the EFA were obtained by drilling at many of the sites shown in figures 1 and 2, with site details provided in tables 1 and 2 . The locations shown in tables 1 and 2 are nominal; the holes drilled to define lithology and obtain samples for lab testing were distinct from the holes drilled to perform borehole erosion tests, but the holes were typically within 10 meters of each other. The sediment characteristics and lithology could therefore differ between holes drilled for different purposes.

The JETs were done above the waterline near sites LAR1, 2, 4, $5,8,9$ on the American River and at sites SAC3 and SAC7 on the Sacramento River.

Erosion rate is commonly assumed to be related to some power of excess shear stress on the sediment (for example, Yang, 1996):

$$
E=k^{*}\left(\tau-\tau_{c}\right)^{p}
$$

Table 1. Approximate locations and depths for drilling sites on the lower American River (LAR), California.

[NA indicates a test not done or halted because of debris. Latitude and longitude are based on WGS 84 datum and were provided by U.S. Army Corps of Engineers along with ground-elevation data. Abbreviations: m, meter; NAVD 88, North American Vertical Datum of 1988; BET, borehole erosion test]

\begin{tabular}{ccccccc}
\hline $\begin{array}{c}\text { Site } \\
\text { name }\end{array}$ & Latitude & Longitude & $\begin{array}{c}\text { Ground elevation } \\
(\mathbf{m}, \mathbf{N A V D} 88)\end{array}$ & $\begin{array}{c}\text { Target hole } \\
\text { depth }(\mathbf{m})\end{array}$ & $\begin{array}{c}\text { Lithology hole } \\
\text { depth }(\mathbf{m})\end{array}$ & $\begin{array}{c}\text { BET Hole } \\
\text { depth }(\mathbf{m})\end{array}$ \\
\hline LAR1 & 38.567043 & -121.37287 & 11.9 & 7.3 & 7.5 & NA \\
LAR2 & 38.567505 & -121.382367 & 13.4 & 8.8 & 8.7 & 2.7 \\
LAR3 & 38.565279 & -121.392356 & 13.1 & 10.7 & 10.7 & 5.2 \\
LAR4 & 38.560523 & -121.411922 & 11.6 & 9.5 & 9.3 & NA \\
LAR5 & 38.560627 & -121.416983 & 11.3 & 9.1 & 9.3 & 3.7 \\
LAR6 & 38.561914 & -121.418805 & 12.5 & 10.4 & 10.7 & 4.9 \\
LAR7 & 38.56643 & -121.421602 & 11.6 & 10.7 & 10.5 & 4.6 \\
LAR8 & 38.572297 & -121.423641 & 11.9 & 11 & NA & NA \\
LAR9 & 38.584124 & -121.425739 & 11.6 & 10.7 & 10.5 & 7.9 \\
LAR10 & 38.589901 & -121.454501 & 9.8 & 11.9 & 11.1 & 4.6 \\
LAR11 & 38.601747 & -121.491249 & 8.5 & 10.7 & 10.5 & NA \\
LAR12 & 38.580259 & -121.425334 & 11.9 & 11 & 11.1 & 6.1 \\
\hline
\end{tabular}

Table 2. Approximate locations, elevations, and hole depths for drilling sites on the Sacramento River, California.

[NA indicates a test not done or halted because of debris. Latitude and longitude are based on WGS 84 datum and were provided by U.S. Army Corps of Engineers along with ground elevation data. Borehole erosion tests (BETs) were done twice at station SAC3, first with water to $3.0 \mathrm{~m}$ and then with drilling mud to $4.6 \mathrm{~m}$. Abbreviations: $\mathrm{m}$, meter; NAVD 88, North American Vertical Datum of 1988; BET, borehole erosion test]

\begin{tabular}{ccccccc}
\hline $\begin{array}{c}\text { Site } \\
\text { name }\end{array}$ & Latitude & Longitude & $\begin{array}{c}\text { Ground elevation } \\
\text { (m, NAVD 88) }\end{array}$ & $\begin{array}{c}\text { Target hole } \\
\text { depth }(\mathbf{m})\end{array}$ & $\begin{array}{c}\text { Lithology hole } \\
\text { depth }(\mathbf{m})\end{array}$ & $\begin{array}{c}\text { BET hole } \\
\text { depth }(\mathbf{m})\end{array}$ \\
\hline SAC1 & 38.595986 & -121.507081 & 8.8 & 11.9 & 8.8 & 8.5 \\
SAC3 & 38.548766 & -121.511313 & 6.4 & 11.9 & 9.5 & $3.0,4.6$ \\
SAC5 & 38.51774 & -121.525996 & 11.3 & 18.9 & 18.9 & NA \\
SAC7 & 38.474598 & -121.531639 & 6.7 & 14.3 & 14.3 & 4 \\
SAC8 & 38.475533 & -121.515974 & 10.4 & 18 & 17.9 & NA \\
SAC9 & 38.464399 & -121.502893 & 5.5 & 13.1 & 13.9 & 5.2 \\
\hline
\end{tabular}


where

$E \quad$ is erosion rate (length per unit time);

$k \quad$ is erodibility coefficient (length per unit time per unit excess shear stress) relating the erosion rate $E$ to the excess shear stress, defined as the difference between the shear stress applied by the fluid ( $\tau$, force per unit area) and the critical shear stress $\left(\tau_{c}\right.$, force per unit area);

$\tau_{c} \quad$ is the minimum shear stress that causes erosion; and

$p \quad$ is often applied as 1 as in this study and controls the type of relation between the excess shear stress and the erosion rate.

The primary goal of each test is to determine two factors:

(1). The critical shear stress, $\tau_{c}$, required to initiate erosion, and

(2). The erodibility coefficient, $k$, relating the erosion rate to the excess shear stress.

Work and Livsey (2020) did not attempt to compute wall shear stress for the borehole erosion test scenarios. The flow in the borehole is analogous to flow in a pipe, but if the shape of the hole becomes sufficiently tortuous, the flow deviates strongly from what is observed in conduits with simpler geometries. Some of the boreholes had deep horizontal crevices that did not experience the higher velocities defined by the simple equation used to compute representative velocities in the hole ( $V=Q / A$, or velocity magnitude equals discharge divided by area). A more refined approach might include the use of computational fluid dynamics (CFD) tools to define velocity throughout the hole, but this was beyond the scope of this investigation and using CFD tools would be impractical because of the level of expertise and effort involved. The other two methods (EFA and JET) make use of computed shear stress, so shear stress had to be estimated for the BET results to compare the three methodologies.

A commonly assumed relation between velocity magnitude and shear stress in a conduit (Munson and others, 2013) was used to estimate wall shear stress $\tau$ in the borehole test scenario:

$$
\tau=\frac{1}{8} \rho f V^{2}
$$

where

$\tau \quad$ is shear stress as appears in equation 2,

$V \quad$ is the local mean velocity magnitude in the conduit,

$\rho \quad$ is the fluid density, and

$f \quad$ is the Darcy-Weisbach friction factor (dimensionless).
The values of $V$ and $\rho$ can be estimated from BET data, but $f$ depends on the degree of turbulence of the fluid (indicated by the dimensionless Reynolds number), borehole geometry, and borehole roughness. Many equations have been proposed to describe the dependence of the friction factor $f$ on the Reynolds number and relative roughness of a pipe (wall roughness height divided by pipe diameter). In most cases, however, full flow through a pipe is assumed rather than the scenario of an annulus between a circular pipe (the drilling rod) and a nominally circular larger conduit (the drilled hole). Lyons and Plisga (1996) recommended the following equation for friction factor $f$ in this scenario:

$$
f=\left[\frac{1}{2 \log _{10}\left(\frac{D_{h}-D_{p}}{e_{a v}}\right)+1.14}\right]^{2}
$$

where

$$
\begin{aligned}
& D_{h} \quad \text { is the diameter of the drilled hole, and } \\
& D_{p} \quad \text { the outside diameter of the drill pipe. }
\end{aligned}
$$

Equation 4 has no dependence on a Reynolds number, as is the case for fully turbulent flow in a pipe. The hole and the pipe typically have different roughness, so an average roughness is used in equation 4 :

$$
e_{a v}=\frac{e_{o h} D_{h}^{2}+e_{p} D_{p}^{2}}{D_{h}^{2}+D_{p}^{2}}
$$

where

$$
\begin{aligned}
& e_{o h} \quad \text { is the representative roughness height for the } \\
& \text { wall of the drilled hole, and } \\
& e_{p} \quad \text { the roughness height for the drill pipe. }
\end{aligned}
$$

Values for these are typically not measured in practice but are instead obtained from reference publications. Munson and others (2013) recommended a value of $0.045 \mathrm{~mm}$ for roughness of commercial steel pipe, so this value was chosen for $e_{p}$. The roughness height for the drilled hole is not easily measured and varies by geographical location and along the length of each hole. For a hole of constant diameter through homogeneous sediment, the wall roughness is defined by the grain size, but heterogeneity due to more complicated geometry or the presence of gravel, cobbles, or roots, complicates efforts to measure wall roughness.

In order to compare BET and EFA test results, a single erosion rate-shear stress pair was desired for each lithological layer and flow rate. Because the hole geometry and roughness can vary within one layer, the following approach was taken to obtain desired results:

(1). Upper and lower bounds were defined for analysis of changes in the borehole profile. This determination was made subjectively and conservatively to avoid the regions near the hole bottom and the casing at the top where flow is convoluted. 
(2). Upper and lower bounds were defined for the layer of interest based on observed lithology.

(3). An averaging interval was defined for analyzing the chosen layer. In this case, 3 centimeters $(\mathrm{cm})$ was chosen, meaning that four or five measurements of diameter were averaged to determine one diameter for a $3-\mathrm{cm}$ thick sediment section. Compute annulus areas for preand post-test conditions.

(4). Corresponding velocity was computed as discharge divided by mean annulus area.

(5). For the $10 \mathrm{~cm}$ below the top of each averaging layer, a representative roughness was determined. To do this, a line was fit through the radius by depth data for the $10-\mathrm{cm}$ region. Most observations of radii do not fall directly on this line. For each measured radius, determine the distance between the observation and best-fit line. Average the results to find a mean deviation from the linear trend. This mean deviation was taken as the local representative roughness height and was typically based on 16 observed radii.

(6). Average roughness was computed using equation 5 and hole roughness was estimated in step 5.

(7). Friction factor was computed using equation 4. Friction factors were typically between 0.03 and 0.04 .

(8). Shear stress was computed using equation 3.

(9). Erosion rate was computed as change in radius divided by duration of the test.

(10). Steps 1-9 were repeated for each of the averaging intervals in the layer of interest.

(11). Average values of the erosion rate and shear stress were computed for each lithological layer.

The 10-cm interval used for definition of the hole wall roughness is somewhat subjective but important. The interval needs to be large enough to resolve the largest bumps and pockets in the wall profile but not so large that the shape of the hole profile deviates strongly from linear for the distance considered. The interval also needs to include enough measured diameters to define a meaningful mean deviation from the linear trend. Using a $10-\mathrm{cm}$ interval, 16 points were available for this computation.

Hole wall roughness was typically an order of magnitude greater than pipe roughness, meaning that the chosen value for representation of pipe roughness was typically not important. Neglecting pipe roughness in equation 5 and assuming $D_{h}$ and $D_{p}$ are nearly equal, the average roughness $e_{a v}$ becomes equal to half of the hole wall roughness: $e_{a v}=$ $e_{o h} / 2$.

The approach described above was used to compute shear stress and erosion rate for each lithological layer in each borehole for each test. Figure 3 shows relations between erosion rates and shear stresses obtained for three lithological layers at site LAR2. Tests were done with three different flow rates at this site, but the upper and lower layers did not demonstrate measurable erosion in one of the tests, so only two results are available for those layers. Results plotted in figure 3 should, per equation 2, show monotonic, linear (when plotted in log space) increases in erosion rate as shear stress increases. Each result does feature a positive slope, and differences between the layers are evident. Similar plots were made for each BET site and can be found in appendix 1 .

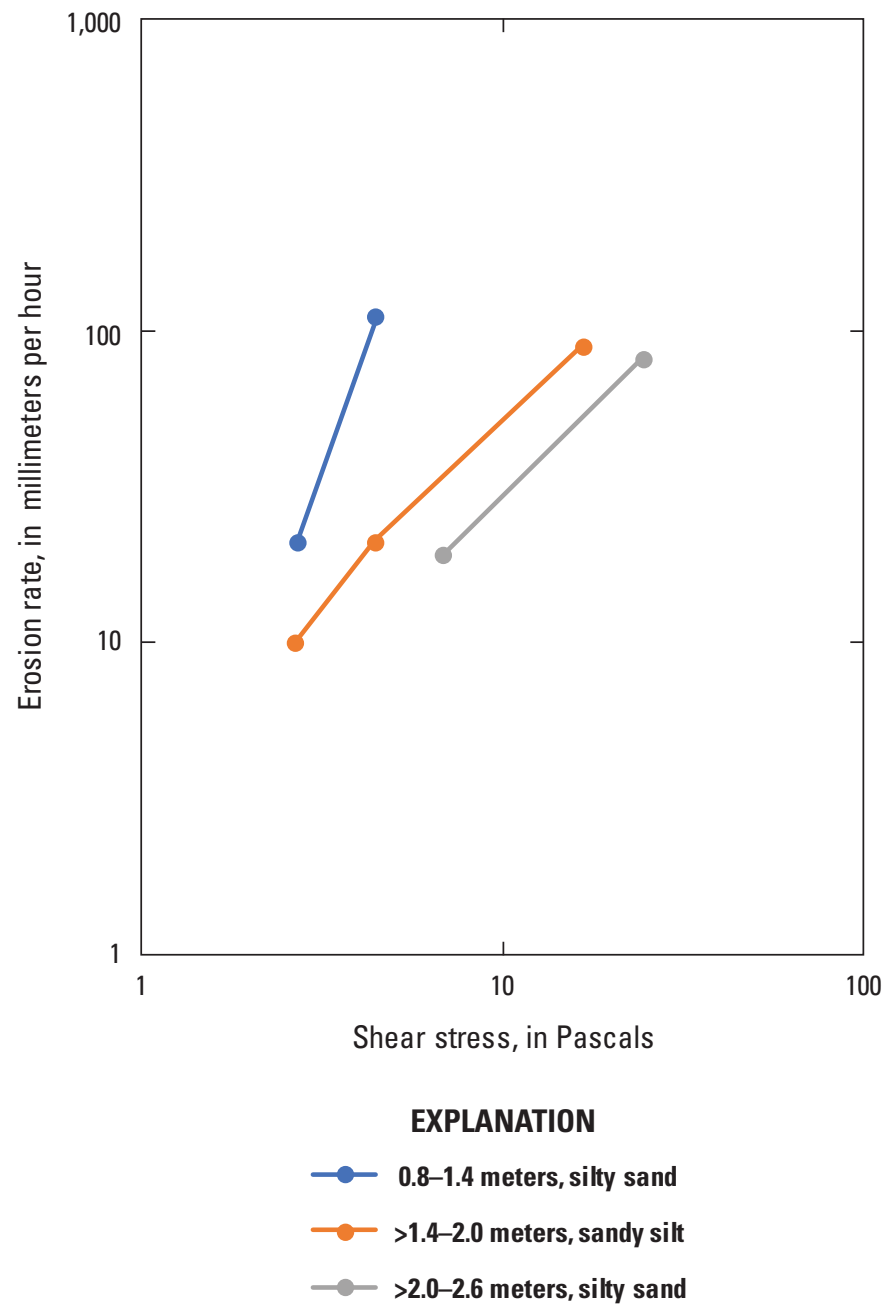

Figure 3. Borehole erosion test (BET) results showing relations between erosion rate and shear stress for three lithological layers at site LAR2 on the lower American River, California. 
Figure 4 shows the BET results for all sites and layers considered superimposed onto one plot. This plot reveals that with few exceptions, observed erosion rates were typically in the 10-100 millimeters per hour $(\mathrm{mm} / \mathrm{h})$ range, with shear stresses in the 1-100 Pascal $(\mathrm{Pa})$ range. Figure 4 also shows the difficulty in attempting to assess critical shear stress using the BET dataset. Briaud and others (2020) attempted to extrapolate the plotted data down to the point where the erosion rate becomes zero and define the corresponding shear stress as the critical value; however, high levels of uncertainty were observed in the BET dataset from this study. Therefore, we did not attempt to extrapolate plotted data or define the critical shear stress value.

Some of the curves in figure 4 have a negative slope, which is inconsistent with the expected result expressed by equation 2 . One test could possibly erode soft material and leave the borehole in a less erodible condition for the second test. In most cases, however, the highest shear stress was during the first test. In this case, a negative slope indicates that a later test with a lower shear stress resulted in a higher erosion rate, which seems unlikely. It is not possible to state conclusively whether the negative slope is correct or a result of measurement error. Most of the tests, however, show a positive slope, consistent with equation 2.

If the critical shear stress is known, and data are collected and processed to reveal a shear stress-erosion rate pair, a value of the erosion coefficient $k$ can be computed from equation 2 . Assuming a value of 1.0 for the exponent $p$ results in the following equation:

$$
k=\frac{E}{\tau-\tau_{c}}
$$

Cores were extracted at each BET site, and Briaud and others (2020) reported EFA test results for many lithological layers. The EFA test can potentially provide much better definition of critical shear stress because the flow speed can be adjusted infinitely as the approach to erosion is observed. For each lithological layer that featured BET data and EFA test data, the critical shear stress result obtained from the EFA test and the shear stress-erosion rate pairs was inserted in equation 6 to estimate $k$. This calculation was repeated for the other BET results for that layer, and the collected results were averaged to determine a representative value of $k$ for the layer. Briaud and others (2020) performed a similar analysis using

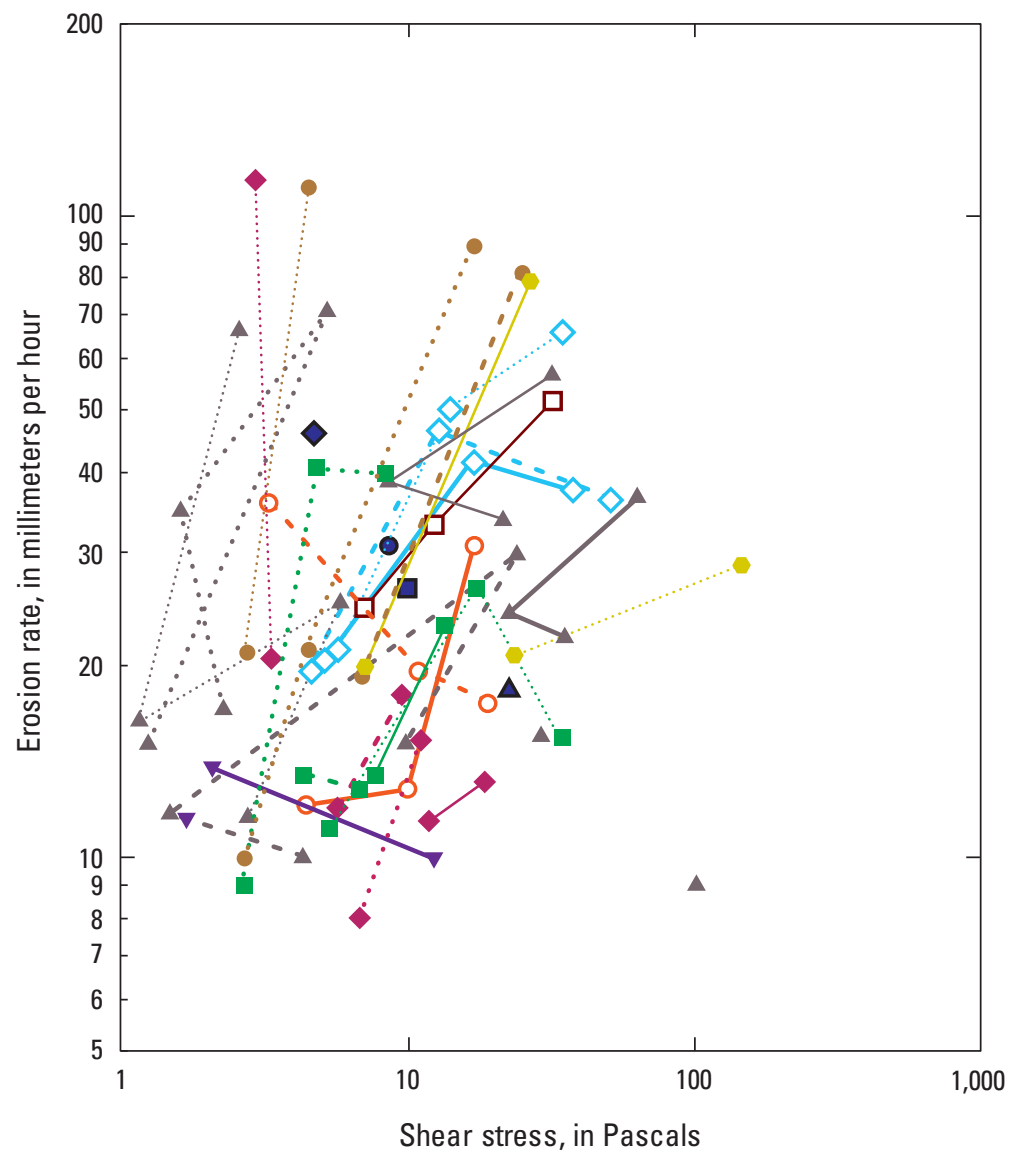

EXPLANATION

Station and depth range, in meters

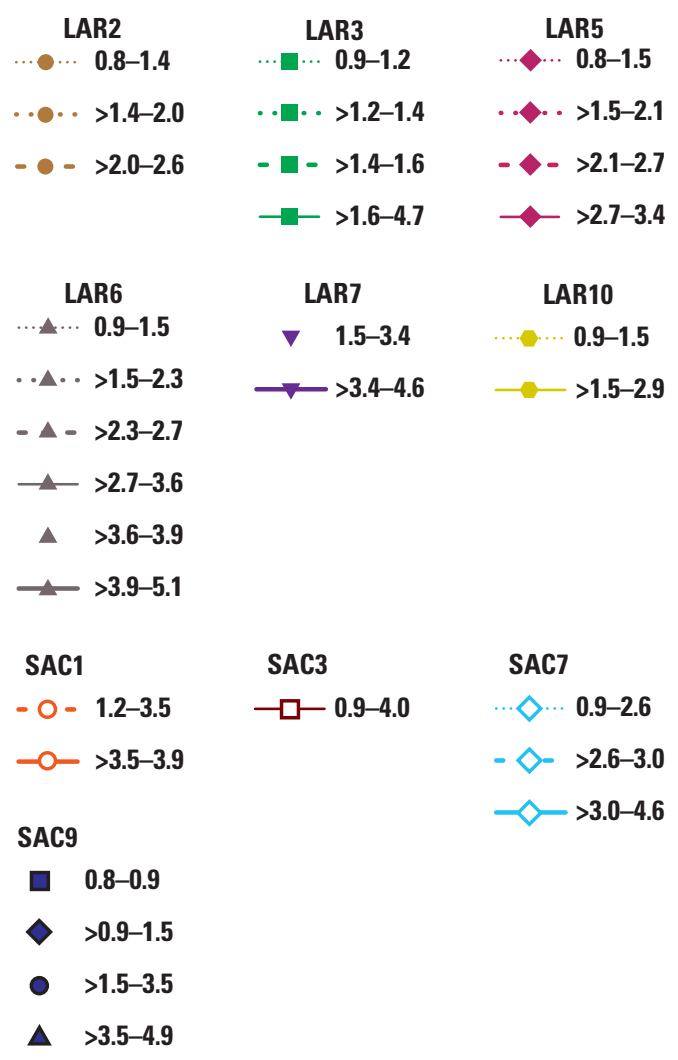

Figure 4. Erosion rate by shear stress plotted for all layers and sites considered in the borehole erosion test (BET) dataset for the American and Sacramento Rivers. 


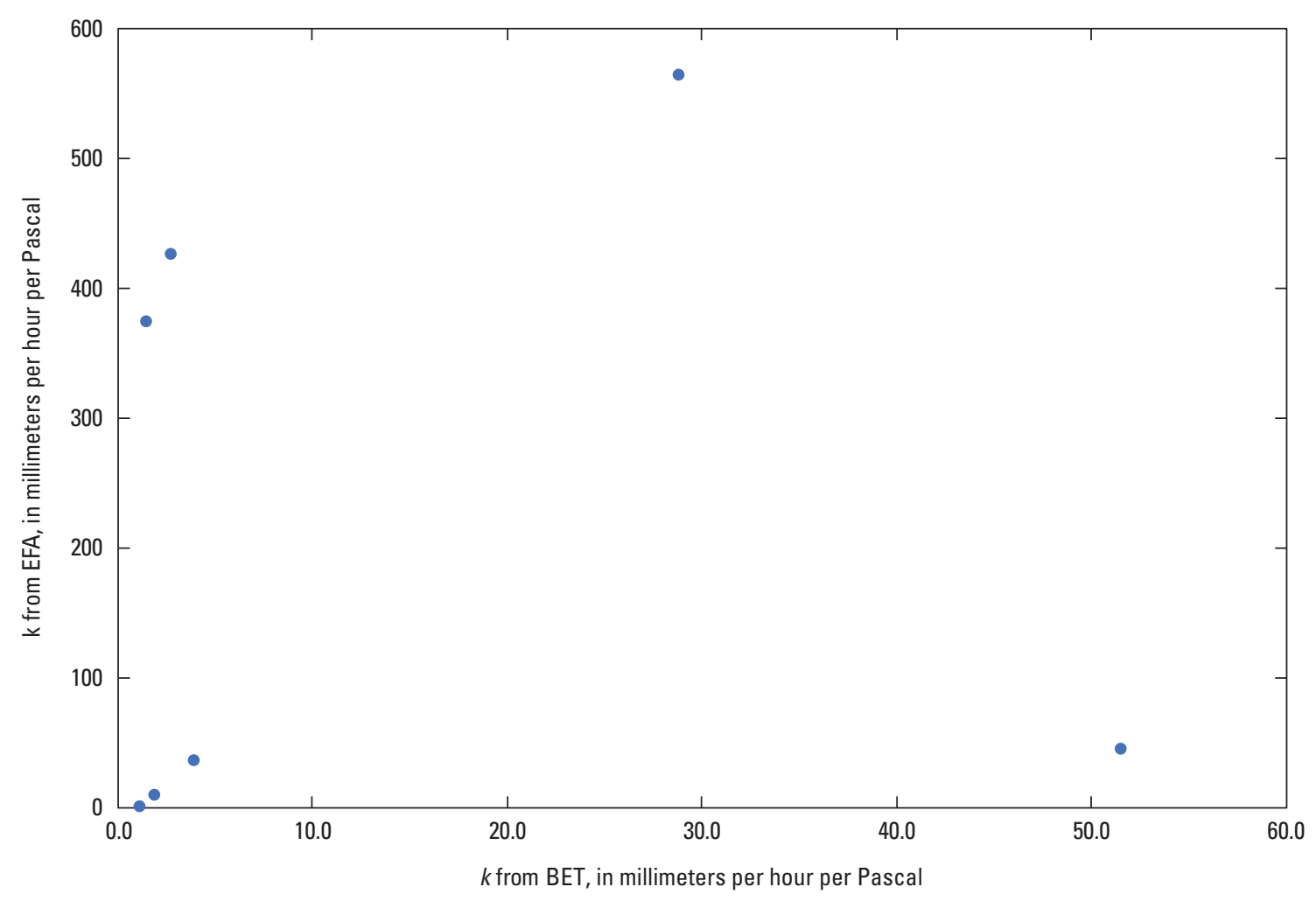

Figure 5. Erosion coefficient $k$ estimated from erosion function apparatus (EFA) test results and reported by Briaud and others (2020) compared to values derived from borehole erosion test (BET) results by the authors for the American and Sacramento Rivers.

the EFA test data to determine $k$ values. A comparison of the two sets of results for $k$ is shown in figure 5. If the two tests produced identical results, the data would plot on a line with a 1:1 slope, but the best-fit values of $k$ from the EFA test are in some cases two orders of magnitude larger than corresponding values from the BET results.

Large differences between erosion coefficients derived from the BET and EFA datasets are also evident in the results presented in Briaud and others (2020), where the BET and EFA results are superimposed on the sample plot for each location. In general, the BET resulted in higher shear stresses and lower erosion rates than the EFA tests.

Uncertainty plays a role in all experimental measurements, and the uncertainty of each variable combined with other uncertainties derived from observed variables used in calculations results in a total uncertainty for the computed quantity. Work and Livsey (2020) concluded that $7.2 \mathrm{~mm} / \mathrm{h}$ was the minimum observable erosion rate in the BET dataset based on caliper resolution and assuming a 10-minute test. Most of the early tests were done for 10 minutes, but with additional experience, the duration was gradually increased to improve the signal-to-noise ratio. One drawback of the BET is that the velocity at a given elevation is constantly changing as the borehole erodes, even if the flow rate is held constant. The flow rate also changes during the test, in part because the shape and roughness of the borehole is changing. Most BET results for erosion are in the $5-100 \mathrm{~mm} / \mathrm{h}$ range. To reach this range, a 10-200 $\mathrm{mm}$ increase in radius would be needed for a 30 -minute test. This increase in radius is one or two orders of magnitude more than the caliper resolution, and the uncertainty associated with the measurement of time is assumed negligible here, so the overall uncertainty in computed erosion rate in the BET results is concluded to be small.

Erosion rates derived from EFA tests reported by Briaud and others (2020) are much higher than the BET results for the same sediments, in some cases exceeding $1,000 \mathrm{~mm} / \mathrm{h}$. Each increment of an EFA test was stopped when $10 \mathrm{~mm}$ of erosion was observed or after 10 minutes had elapsed. To reach $1,000 \mathrm{~mm} / \mathrm{h}, 10 \mathrm{~mm}$ of sediment must erode in 0.01 hours, or 36 seconds. Therefore, a timing error of 1 second would result in a 3 percent error in the computed erosion rate. This uncertainty is inconsequential, however, compared to the large differences between the EFA- and BET-derived erosion rates. Both tests reveal erosion rates averaged for a testing period of similar duration, with a similar range of velocities, although some very high localized velocities were observed occasionly in borehole tests. The BET is likely to have more variability in velocity during a given test, but given the nonlinear relation between erosion rate and velocity, with all other factors being equal, this relation would tend to make the BET result for erosion rate greater than the EFA result, which is the opposite of the observed trend. Part of the difference between test results may be that one test was in situ and the other a laboratory test of extracted sediment that was reconstituted in some cases. 
The EFA also requires some judgment when deciding how fast to advance the test cylinder. An order of magnitude difference in the erosion rate seems unlikely to arise from either of these issues, but the difference in results does exist at many of the sites. Likewise, in each case, the EFA samples were obtained from a different hole than the one in which the BET was done. EFA holes were generally within $10 \mathrm{~m}$ of the BET holes, but material in the EFA holes could have been more erodible than material in the neighboring BET.

The computed shear stress depends on fluid density, mean flow speed, and a friction factor that depends on roughness of the sediment surface. The quadratic dependence on flow speed, and flow speed time dependence arising from time dependences in discharge and annulus geometry, makes flow speed a potentially large contributor (eq. 3) to uncertainty in the mean shear stress. The friction factor depends on a roughness that is often chosen based on previously published values based on sediment type and thus contains subjectivity. The approach in this report differs from that of Briaud and others (2020) for the same dataset, but the results for computed shear stress for the borehole tests are very similar. Different choices could easily lead to a systematic increase or decrease of 10-20 percent. Likewise, the shear stress in the EFA test could be over- or underestimated, depending on assumptions invoked.

Comparison of the EFA and BET results shown by Briaud and others (2020) reveals two systematic differences: the erosion rates are higher and shear stresses are lower in most of the EFA tests. Friction factors were determined in similar fashions in each case but included some subjectivity. Briaud and others (2020) took "one half of the depth of the asperities on the sample surface" as the representative roughness for the EFA tests and used borehole geometry to define relative roughness for the BET approach. Visual assessments of roughness height were used to define roughness for EFA and BET tests. If the borehole contained bumps and pockets that were not present in the EFA test sample, the borehole was subject to higher shear stresses at the same velocity because the friction factor was greater when roughness was enhanced by more complicated geometry. Inadequate representation of borehole geometry does not, however, explain the trend of observed lower erosion rates in the borehole tests compared to the EFA results at higher shear stresses.

Langendoen and Ursic (2020) described the application of the JET apparatus, surveying of riverbank profiles, and sediment collection at designated locations throughout the study area. JET tests were performed at six sites on the lower American River (LAR1, LAR2, LAR4, LAR5, LAR8, LAR9, fig. 1) and two study sites on the Sacramento River (SAC3, SAC7, fig. 2). At seven of these eight sites either a BET or EFA test was also done, but only three sites featured all three tests. Comparing results from different methods directly is problematic because site designations are nominal, and the actual test locations differed by tens of meters. Another issue is that JETs provide an estimate of critical shear stress and erosion coefficient for bed-surface sediments, but the BET and EFA tests provide estimates of these parameters at depths beneath the bed. For comparison purposes, BET and EFA results nearest the bed surface were selected. Where more than one estimate was available for a given test site in a given layer, results were averaged. All estimates of critical shear stress and erosion coefficient $k$ for EFA test and BET used in this section were taken from Briaud and others (2020).

Langendoen and Ursic (2020) reported three estimates each for critical shear stress and the erosion coefficient, using methods referred to as Blaisdell, iterative, and regression; the last of these is the simplest in that it is a linear fit through the data. In some instances, the three methods provide very different results, and large differences often were observed among repeated tests. Table 3 provides one example, where critical shear stresses and erosion coefficient values computed using the iterative and regression methods were more than an order of magnitude larger than values computed using the Blaisdell method, and differences among the repeated tests span more than an order of magnitude.

Figure 6 compares critical shear stresses estimated by Langendoen and Ursic (2020) by the three cited approaches. Critical shear stresses computed using iterative and regression methods are similar and are much higher than critical shear stresses computed using the Blaisdell method. The estimates from all three methods are also much larger than the estimates derived from the BET and EFA test data (fig. 7), which are not directly comparable because of the different depths assessed.

Estimated values of the erosion coefficient $k$ derived from the JETs were highest using the iterative method and lowest using the Blaisdell method (fig. 8). In this study, on the rising limb of a hydrograph, the Blaisdell method indicates the earliest onset of erosion but slower erosion after onset compared to the other two methods. The iterative and regression methods have similar values of critical shear stress, but for a given shear stress above the critical value, the iterative method results in the highest estimated erosion rate at most sites. The JET results from the regression approach were chosen for use in the model described in the next section.

Figure 9 shows the erosion coefficients derived from EFA tests reported by Briaud and others (2020) for the stations where EFA test and JET data were both available.

Table 3. Critical shear stresses at station LAR8 on the American River, California, as reported by Langendoen and Ursic (2020). Each of the three results at each site corresponds to a different approach to fitting a curve through a set of erosion rate to shear stress data points.

[Pa, Pascal]

\begin{tabular}{cccc}
\hline \multirow{2}{*}{ Test } & \multicolumn{3}{c}{ Critical shear stress (Pa) } \\
\cline { 2 - 4 } & Blaisdell & Iterative & Regression \\
\hline 1 & 0.186 & 4.96 & 4.23 \\
2 & 0.007 & 0 & 1.45 \\
3 & 0.349 & 6.76 & 8.03 \\
Mean & 0.181 & 3.91 & 4.57 \\
\hline
\end{tabular}




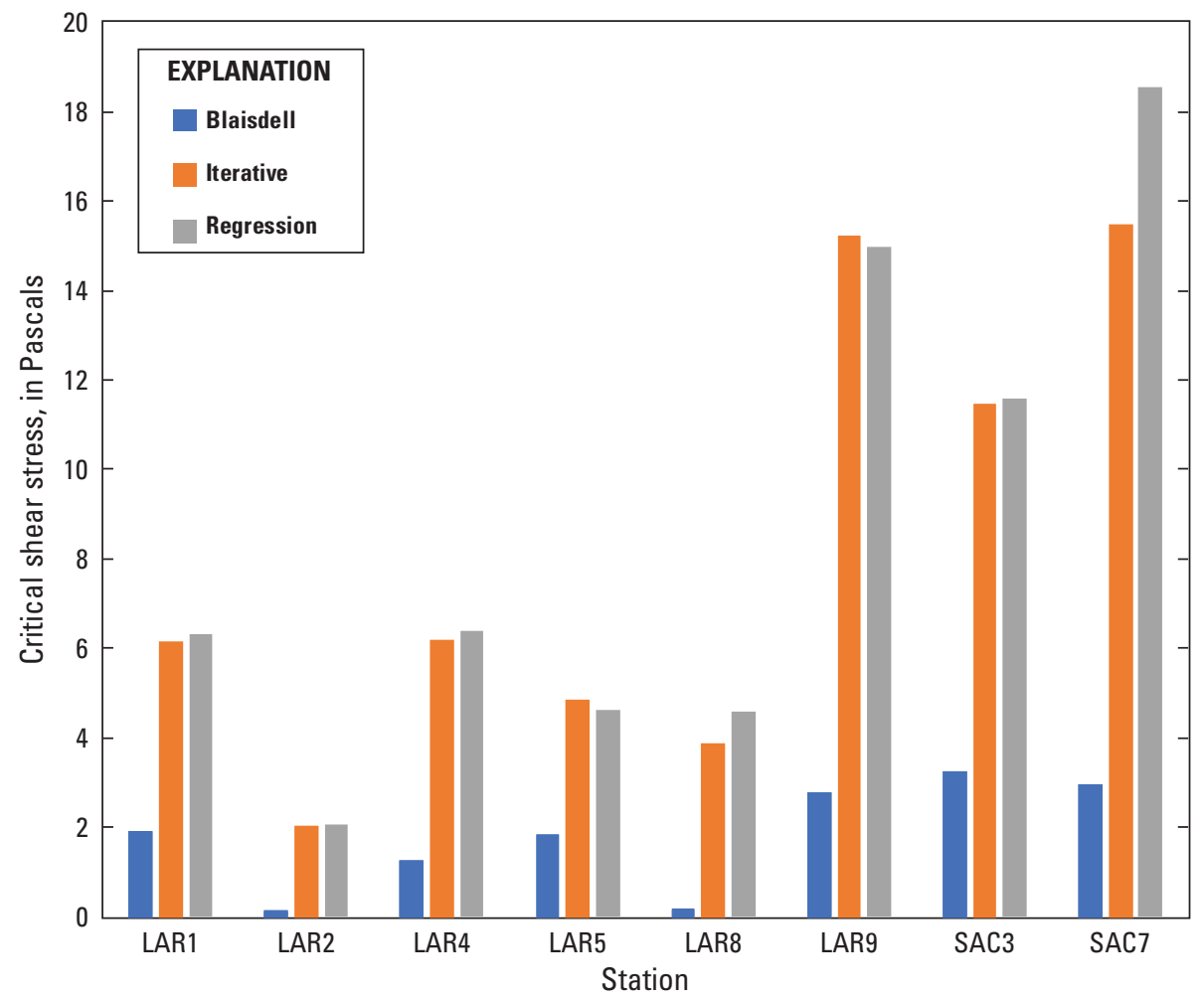

Figure 6. Critical shear stresses from jet erosion tests (JETs) reported by Langendoen and Ursic (2020) for the American and Sacramento Rivers, California. Each result represents an average of all available results at a given location for surface sediments.

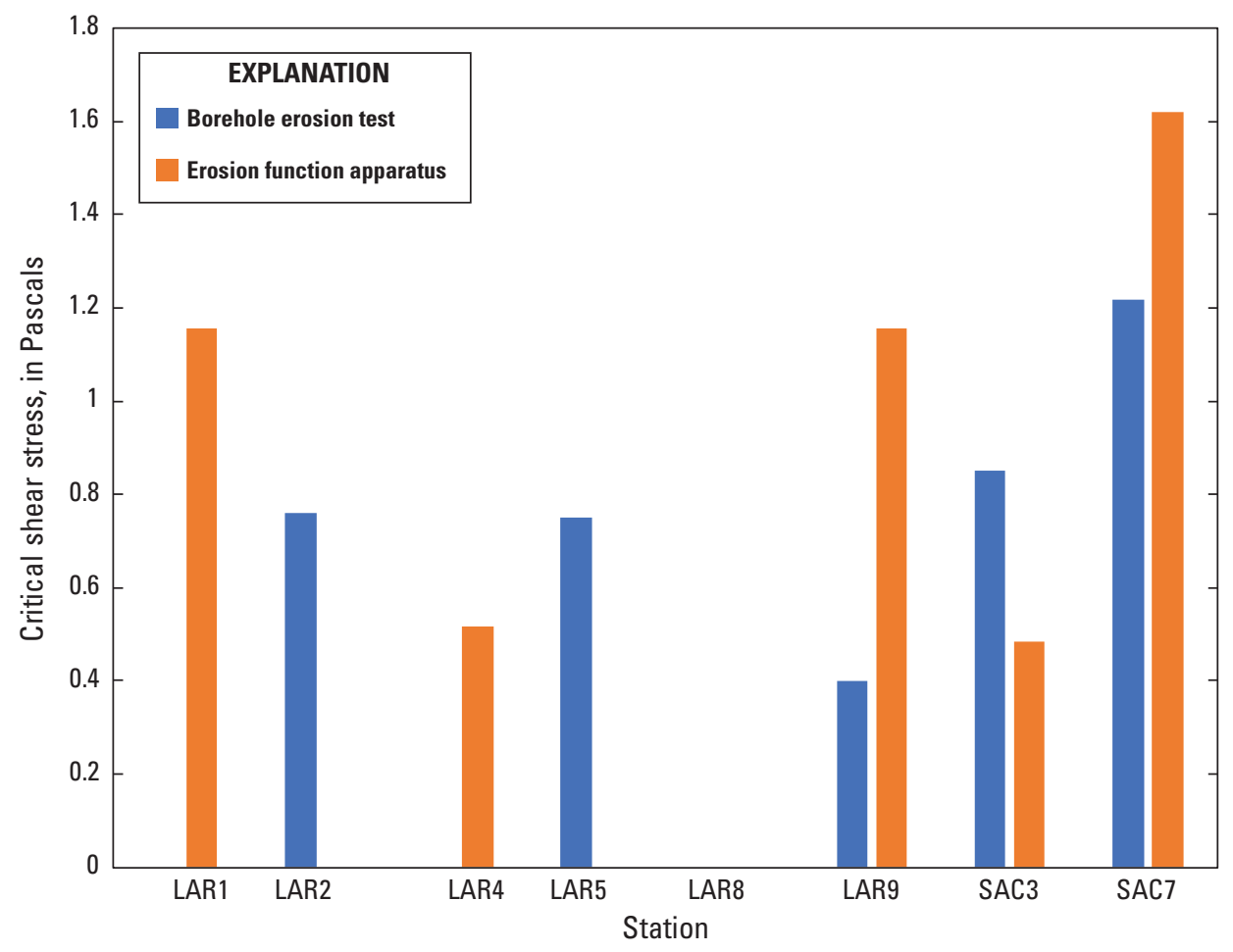

Figure 7. Critical shear stresses reported by Briaud and others (2020) for borehole erosion tests and erosion function apparatus tests for the American and Sacramento Rivers, California. Depths of regions or samples analyzed vary. Repeated tests are averaged where available. 


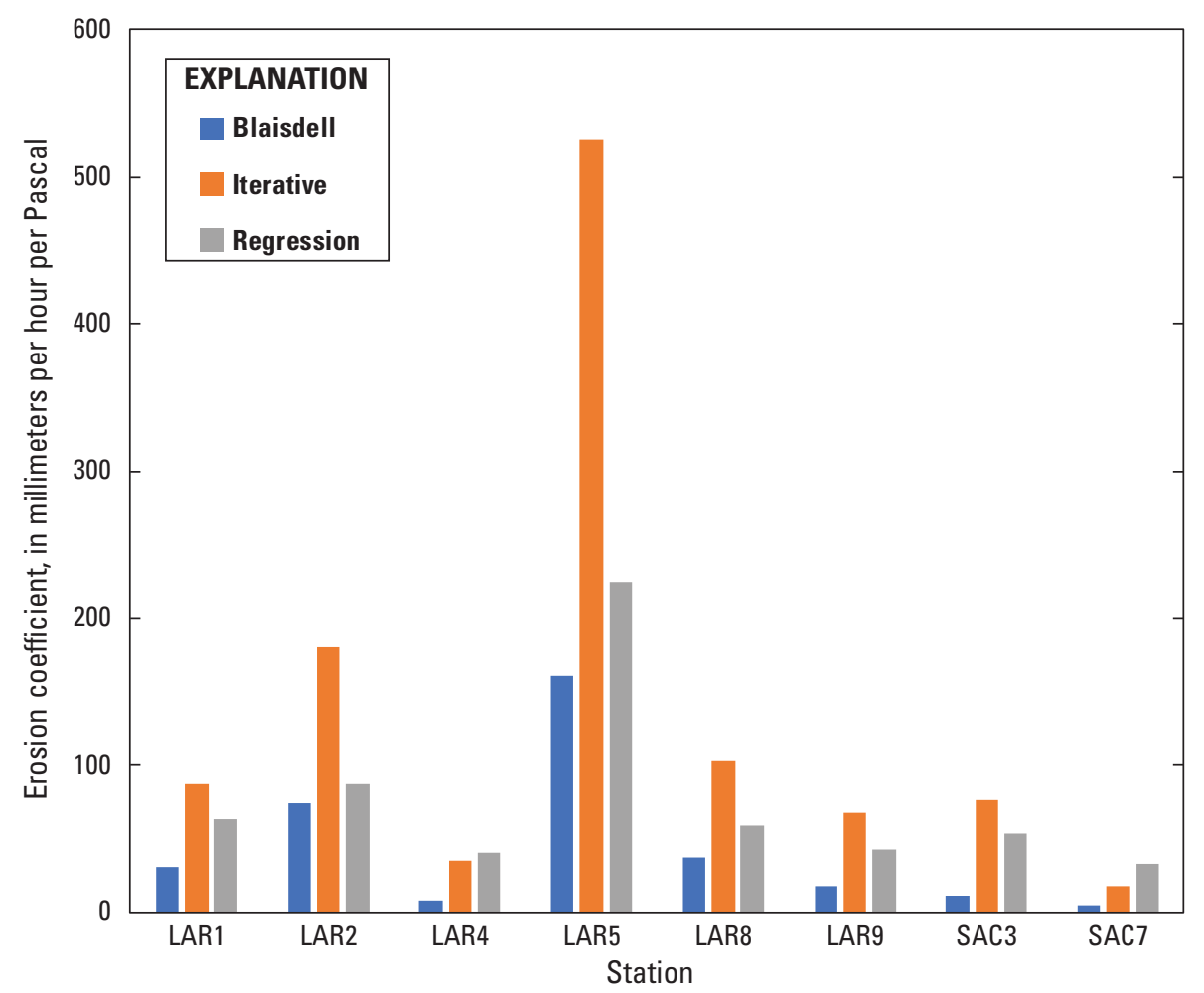

Figure 8. Erosion coefficients $k$ derived from jet erosion test (JET) results reported by Langendoen and Ursic (2020) for the American and Sacramento Rivers, California.

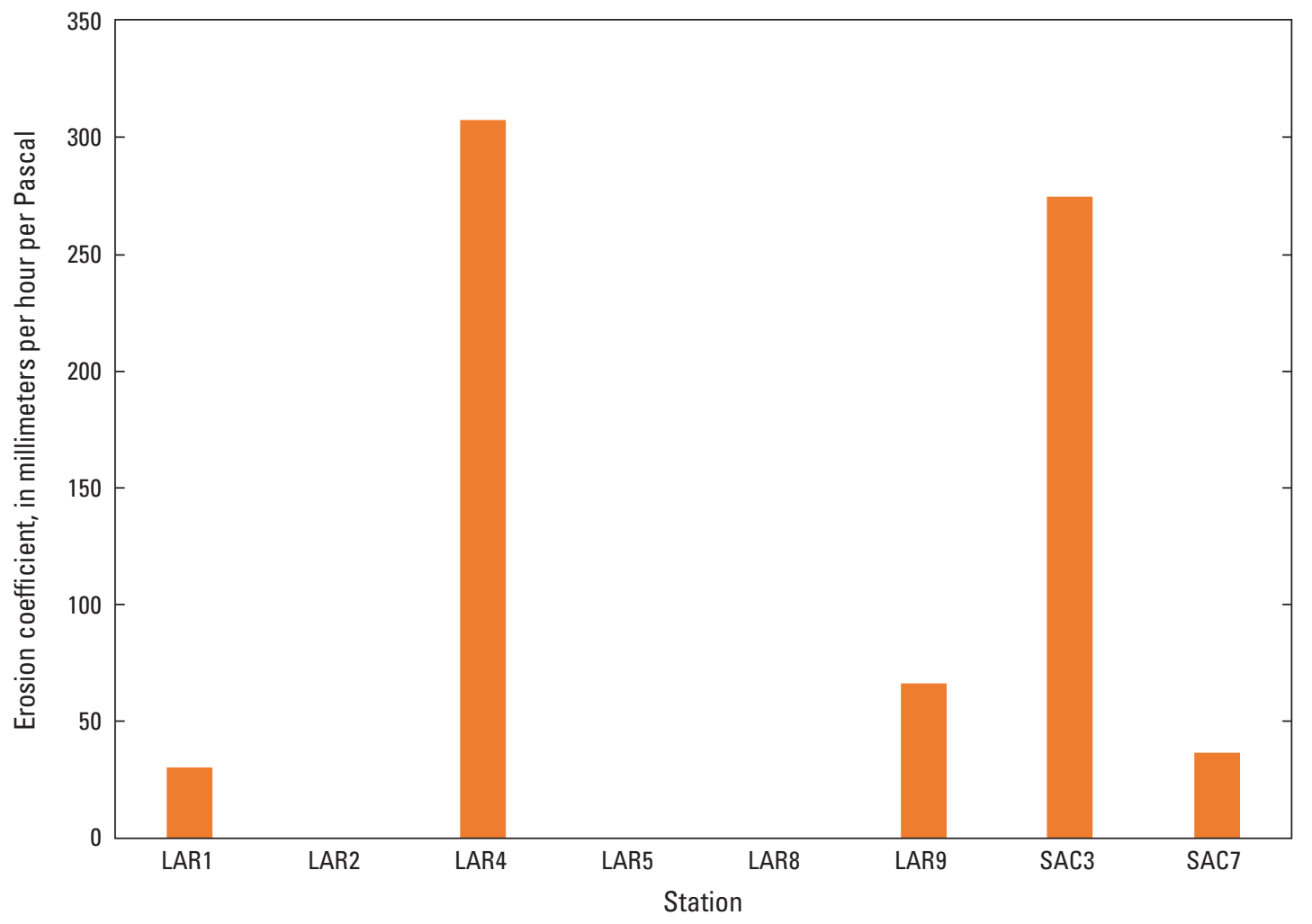

Figure 9. Estimates of erosion coefficient $k$ derived from erosion function apparatus (EFA) tests and reported by Briaud and others (2020) for the American and Sacramento Rivers, California. 


\section{Equilibrium Model for Cross-Section Erosion}

Most physical systems reach an equilibrium state when subjected to constant forcing for a sufficiently long period, meaning that the response to the constant forcing goes to zero. This idea was applied to cross-section data along the American and Sacramento Rivers to simulate the equilibrium cross section that could result from a constant, high flow rate. Available surveyed cross sections provided to the authors by USACE, HEC-RAS model (U.S. Army Corps of Engineers, 2016) outputs describing velocities at the peak of a major flood on the American and Sacramento Rivers, and erodibility test results described previously were used to simulate equilibrium cross sections.

Cross-section data and simulated velocities for a 200-year peak-flow event for the American and Sacramento Rivers were obtained from the U.S. Army Corps of Engineers' Sacramento District office in the form of HEC-RAS input files. Input files included many surveyed cross sections represented by $\mathrm{x}-\mathrm{y}$ pairs designating (1) distance from an arbitrarily chosen benchmark defining the start of cross sections nominally perpendicular to flow and (2) elevation relative to the NAVD 88 datum. Figure 10 provides an example of the surveyed cross section nearest to station LAR4, with the peak water level reached during a simulated 200-year peak-flow event on the American River shown by a horizontal blue line. Note also that the 200-year peak discharge on the American River in the HEC-RAS simulation exceeds that reported for the Sacramento River.

The HEC-RAS simulation developed by USACE involved dividing each cross section into three zones, designated here as left (river left), center, and right (river right), as viewed looking downstream. Each zone can have a different specified roughness. At a given instant, each zone has one representative velocity in the model. In figure 11, these zones are shown by different colors, indicating different flow speeds in each region. Most American River cross sections considered were fundamentally similar, with the three zones corresponding to main channel (center) and left and right overbank areas. In contrast, the Sacramento River cross sections studied had very narrow left and right overbank regions in the model and appeared as one large main channel between two levees.

The 200-year event simulated in the HEC-RAS model featured nearly five continuous days of very high flows. Figure 12 shows the hydrograph for the American River near Fair Oaks (USGS Station 11446500; U.S. Geological Survey, 2021), slightly upstream from all test sites. The peak discharge shown here was simulated in the cross-section evolution model. Major sources or sinks for water in the region were not simulated for this report, which focused on the American River downstream from a small dam and the Sacramento River downstream from its junction with the American River (figs. 1, 2).
The JET test results (Langendoen and Ursic, 2020) were used to establish relations between the erosion rate and bed shear stress. Equation 2 relates erosion rate $E$ to excess shear stress (Yang, 1996), with the term "excess" denoting the portion above the critical value. To apply the equation, site specific values of critical shear stress, the erosion coefficient $k$, and the exponent $p$, are needed. The exponent $p$ was set to one. After considering the BET, EFA test, and JET results, JET results were used to specify the remaining two empirical parameters in the model. Of the three results for each test presented by Langendoen and Ursic (2020), critical shear stresses and erosion coefficients derived using linear regression were chosen. The rationale for this decision is as follows: (1) the JETs were done on the bed surface and provide better estimates of initial erodibility, and (2) results obtained from the regression approach were similar to results obtained using the iterative approach presented by Langendoen and Ursic (2020), but the regression approach is simpler than the Blaisdell or iterative approaches. As shown by the preceding equations and in the results below, the model is sensitive both to the critical shear stress and the erosion coefficient. These two parameters are a major source of uncertainty when attempting to simulate response of the river to a flood.

Table 4 shows the chosen values of critical shear stress and erosion coefficient for each of the sites where JET data were available and provides initial bed shear stresses for each of the three flow zones at each cross section. Bed shear stress changes as the cross section enlarges during an erosional period.

For each cross section, the input data to the cross-section evolution model consist of the following:

(1). Peak-flow discharge, $Q$, is taken as constant in time, but each station can have different values, if desired.

(2). Bed shear stress at time of peak water level in each of the three regions of the channel cross section, from HEC-RAS output.

(3). Surveyed channel cross-section geometry from HEC-RAS.

(4). Horizontal coordinates defining the lateral boundaries of the three flow regions in each cross section.

(5). Values for critical shear stress and erosion coefficient ( $\tau_{c}$ and $k$ in equation 2 ) that are unique to each cross section.

(6). Water-surface elevation corresponding to the peak discharge.

(7). A peak-flow duration of 120 hours was used for all simulations, and the model time step was 1 hour. 


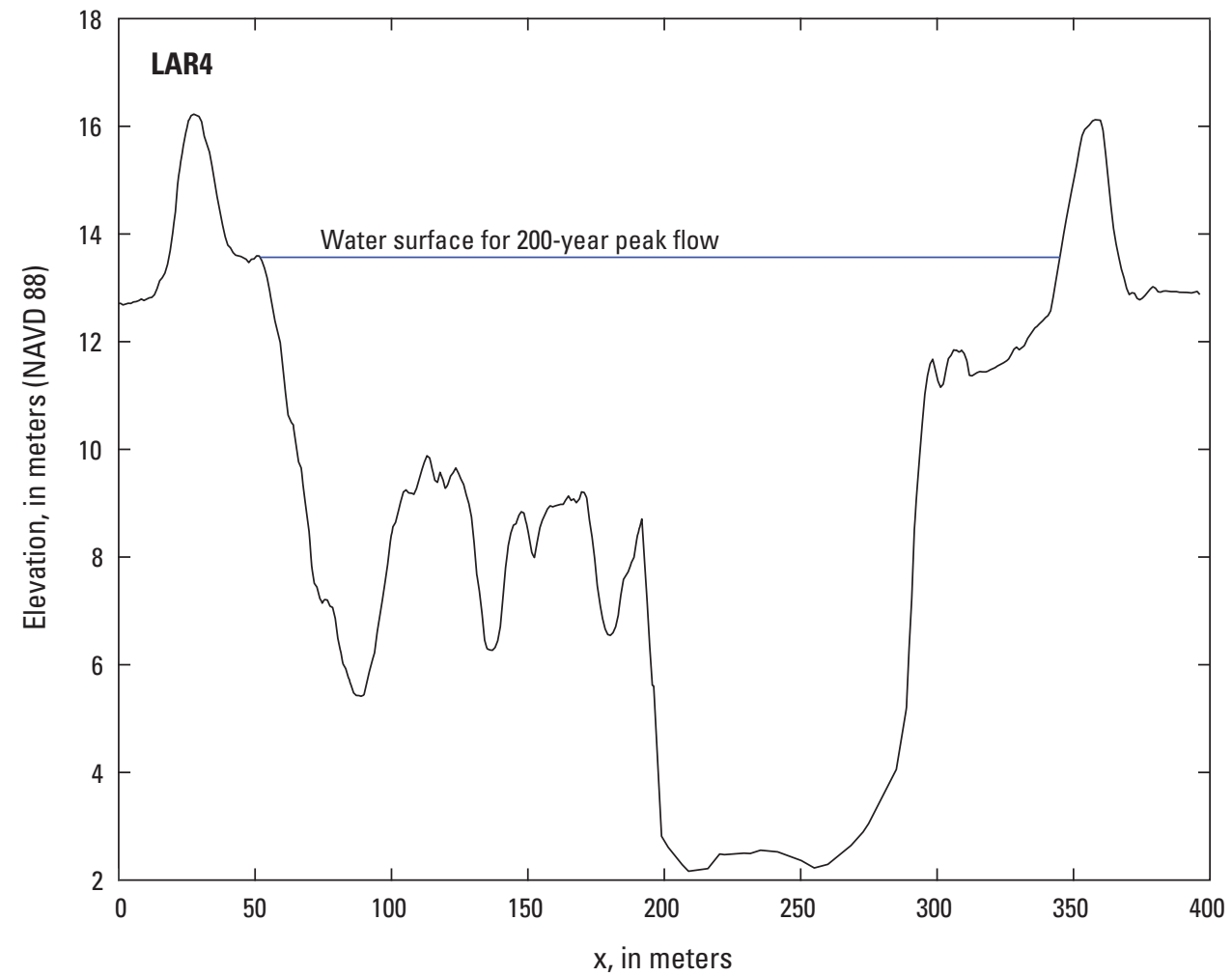

Figure 10. Cross section at station LAR4 on the lower American River, California (see fig. 1 for location), as viewed looking downstream.

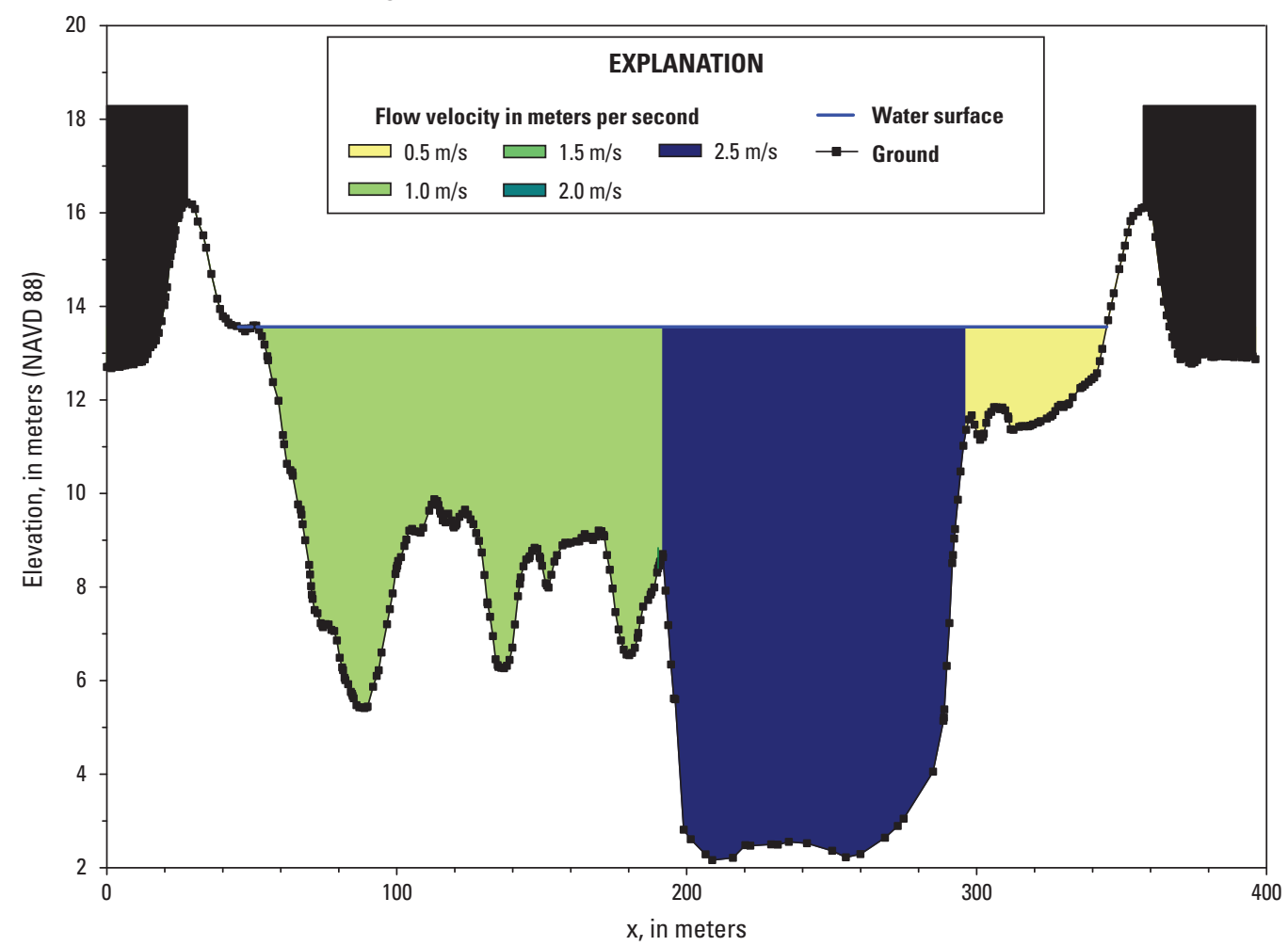

Figure 11. HEC-RAS plot showing cross section at station LAR4 on the lower American River, California, and the division of the channel cross section into left, center, and right computational zones, with each zone having one flow speed. Horizontal coordinates defining the boundaries of each zone were provided in HEC-RAS input and output. 


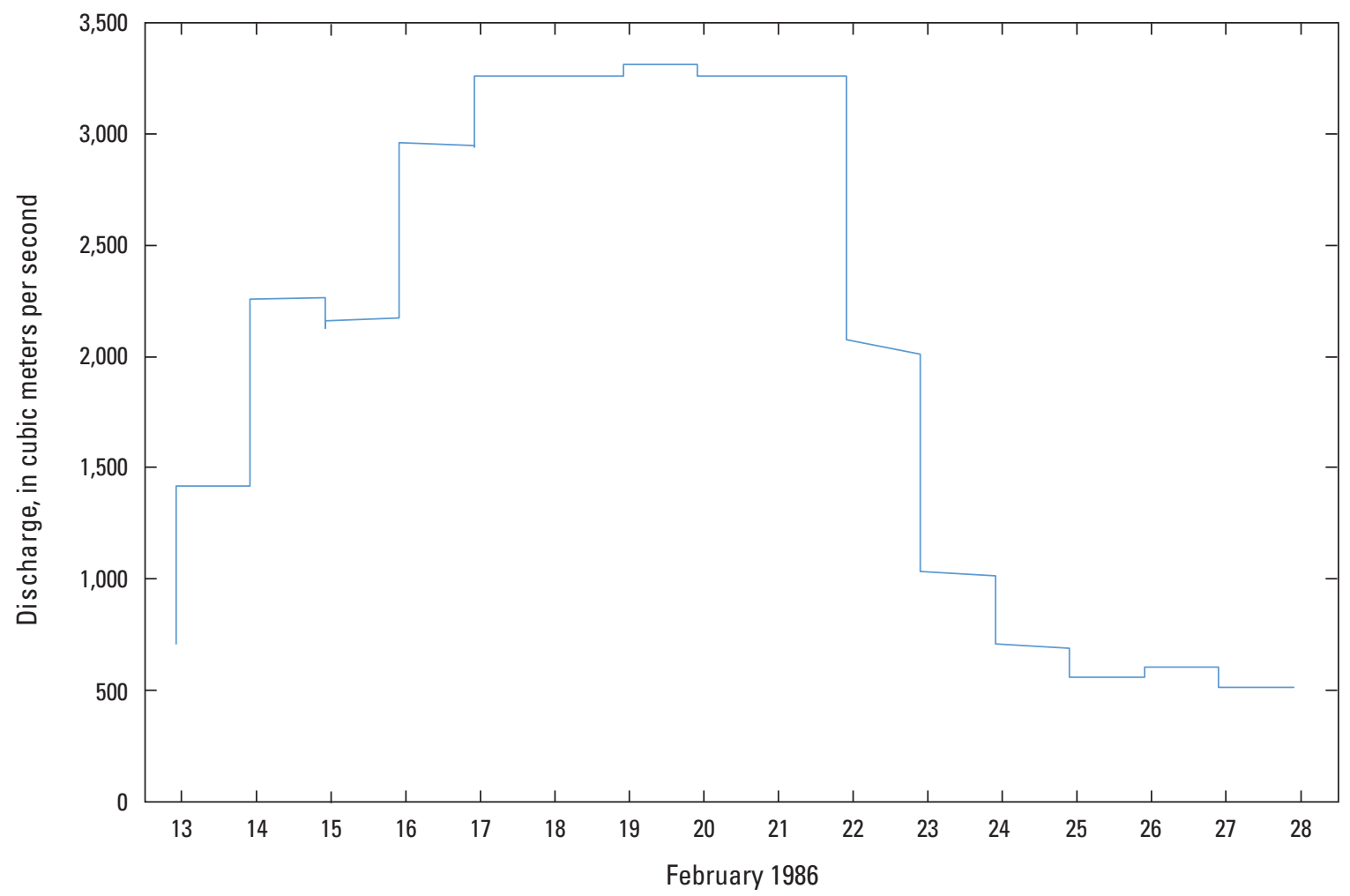

Figure 12. Simulated 200-year peak-flow event on the lower American River, California, in HEC-RAS model.

Table 4. Erosion model parameters (from Langendoen and Ursic, 2020) and initial values of bed shear stress (from U.S. Army Corps of Engineers HEC-RAS simulation).

[Stations shown are those for which measured critical shear stresses were reported by Langendoen and Ursic (2020). The $\tau_{c}$ denotes critical shear stress to initiate erosion, and $\tau_{l}, \tau_{c e n t e r}$, and $\tau_{r}$ denote initial bed shear stress in the left, center, and right zones of the channel, respectively. Abbreviations: $k$, erosion coefficient; Pa, Pascal; $\mathrm{mm} / \mathrm{hr}$, millimeter per hour]

\begin{tabular}{cccccc}
\hline Station name & $\tau_{\boldsymbol{c}} \mathbf{P a}$ & $\boldsymbol{k} \mathbf{m m} / \mathbf{h r} / \mathbf{P a}$ & $\tau_{\boldsymbol{l}} \mathbf{P a}$ & $\tau_{\boldsymbol{c e n t e r}} \mathbf{P a}$ & $\tau_{\boldsymbol{r}} \mathbf{P a}$ \\
\hline LAR1 & 6.34 & 67.8 & 10.5 & 41.2 & 15.3 \\
LAR2 & 2.05 & 87.3 & 15.3 & 30.6 & 6.22 \\
LAR4 & 6.38 & 40.3 & 16.8 & 33.5 & 5.75 \\
LAR5 & 4.63 & 224 & 16.8 & 50.8 & 11.5 \\
LAR8 & 4.57 & 58.4 & 2.39 & 53.2 & 12.9 \\
LAR9 & 15 & 42.3 & 3.35 & 18.2 & 2.87 \\
SAC3 & 11.6 & 53.8 & 0.96 & 12.9 & 2.39 \\
SAC7 & 18.5 & 33.2 & 0.96 & 8.14 & 1.44 \\
\hline
\end{tabular}


The model simulates only erosion in response to increased bed shear stresses. Downstream deposition of sediment is not included. The model code was written to be executed using MATLAB software (Mathworks, Inc., Natick, Mass.)

The model does not solve the energy equation for flow like HEC-RAS does, but the model does ensure that water mass is conserved. Each of the three flow zones (left, right and center) is evaluated to determine an erosion rate based on the shear stress in that region. In each zone, a new depth is computed at the end of the time step, with the depth change given as the erosion rate times the time step. Erosion increases the area of at least a portion of the channel cross section and decreases the velocity and shear stress in the eroding area if discharge is constant. It is possible for each flow zone to evolve at a different rate, however, and for the flow to be redistributed between zones as they erode differentially.

Using subscripts $\ell$, center, and $r$ to denote left, center, and right regions, respectively, the total discharge in the channel, $Q$, can be designated as shown:

$$
Q=V_{\ell} A_{\ell}+V_{\text {center }} A_{\text {center }}+V_{r} A_{r}=\text { constant }
$$

At the end of a time step, new areas can be computed based on the eroded cross-section geometry, and the discharge is known. Two more equations are required to allow computation of the three velocities, however:

$$
\begin{gathered}
\frac{V_{\ell}}{V_{\text {center }}}=k 1 \\
\frac{V_{r}}{V_{\text {center }}}=k 2
\end{gathered}
$$

where

$k 1$ and $k 2 \quad$ are empirical coefficients evaluated at the start of the model run that remain constant.

These equations indicate that the shape of the velocity distribution, in the plan view, does not change as the profile evolves. Based on the assumption that coefficients remain constant, once the new areas have been evaluated at the end of a time step, the center velocity can be computed:

$$
V_{\text {center }}=\frac{Q}{\left[k 1 * A_{\ell}+A_{\text {center }}+k 2 * A_{r}\right]}
$$

Finally, equations 8 and 9 are used to compute $V_{\ell}$ and $V_{r}$.

When the velocities change in the cross section, the bed shear stress also changes. Bed shear stress was assumed to be proportional to the square of velocity (Munson and others, 2013):

$$
\tau=\alpha V^{2}
$$

The coefficient, $\alpha$, includes bed roughness and water density, which remain constant during the simulation period. Thus, $\alpha$ was evaluated during the initial time step as the ratio of bed shear stress to the square of velocity for each zone and also remained constant. Once a time step was completed, new velocities were computed for each zone as described previously, and new shear stresses were computed for each zone using equation 11.

The new model continues in time until either the end of the simulation period is reached or the bed shear stress in each zone drops below the critical shear stress for each zone, which is defined as the equilibrium condition. Note that erosion could modify surface-water levels, but this effect was not simulated. Furthermore, erosion at one cross section could result in deposition at a downstream cross section; however, the model only simulates erosion and does not simulate deposition.

The major assumptions inherent in the model can be summarized as follows:

(1). Clear water conditions. Shear stress and erosion rate are not influenced by suspended sediment concentration.

(2). Only erosion is simulated. Material eroded from one cross section cannot be deposited at a downstream section.

(3). Erodibility of sediments does not vary within a cross section.

(4). Water mass is conserved, but momentum is not. As a cross section erodes, velocities change, but water level does not.

(5). Flow is in the downstream direction only.

(6). Bank failure processes are not considered.

(7). Shear stress in each section of a cross section is constant

(8). Roughness in a section of a cross section is constant.

(9). Lateral erosional processes are not included.

Applying the model at station LAR4 generates the results shown in figure 13. The initial shear stress in the right zone decreases below the critical velocity, so erosion does not occur in the right zone. The left zone eroded slightly, but the erosion ceased by the 20-hour mark. The center section eroded by 15 $m$ and was still eroding when the model stopped at the end of the simulated 120 hours.

The erosion results shown in figure 13 are unrealistic, because they lead to very steep slopes at the transitions between flow zones. In reality these steep sections would be likely to fail because of slumping, resulting in some erosion in the left and right zones and potential deposition in the center zone. Knowing the area of the eroded section and the waterline width, an average vertical erosion can be computed and applied to the entire underwater portion of the cross section as the computed change in area divided by channel width. The result is shown by the curve labeled "uniform" in figure 14 . 


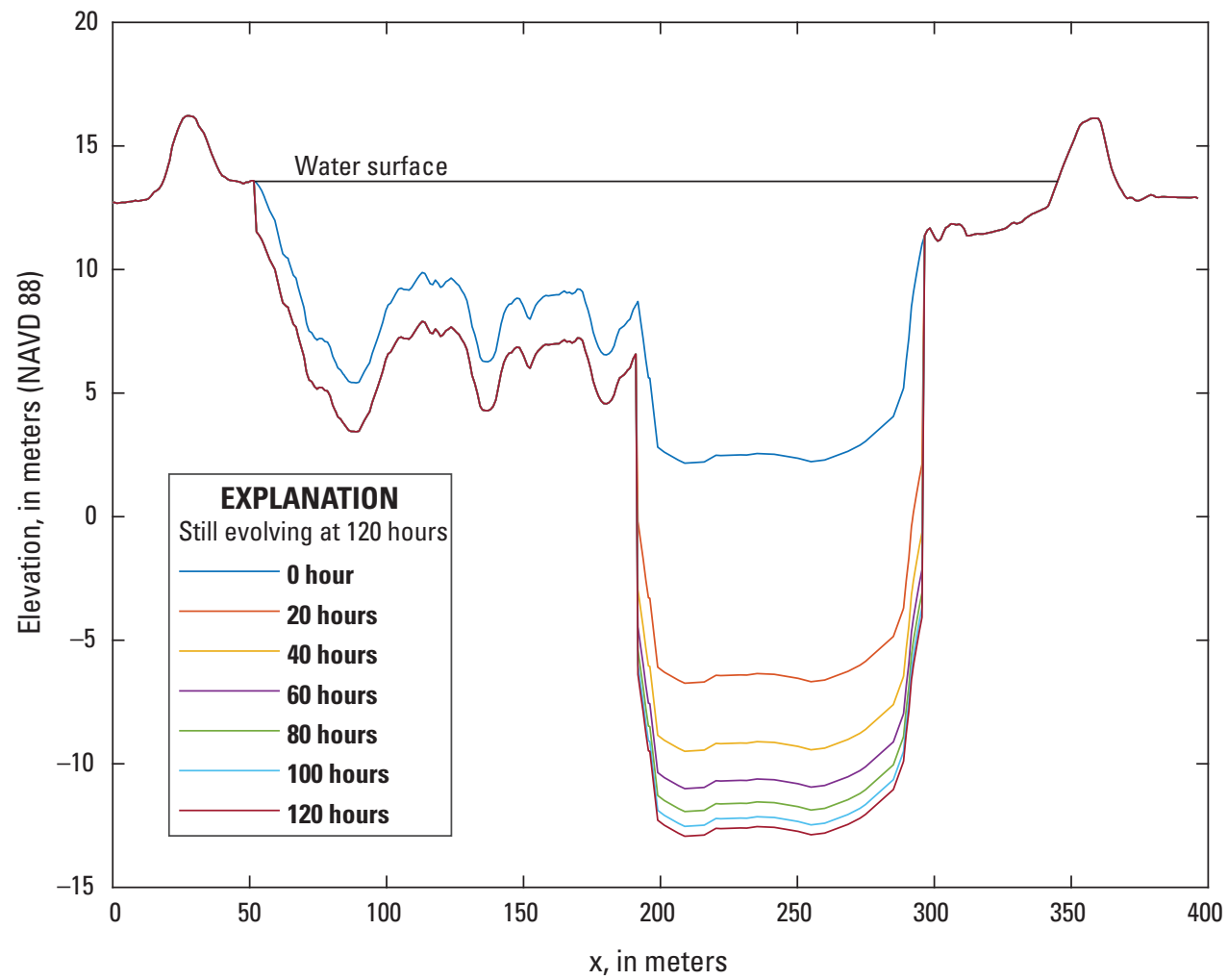

Figure 13. Simulation of erosion response to a 200-year peak-flow event at station LAR4 on the lower American River, California.

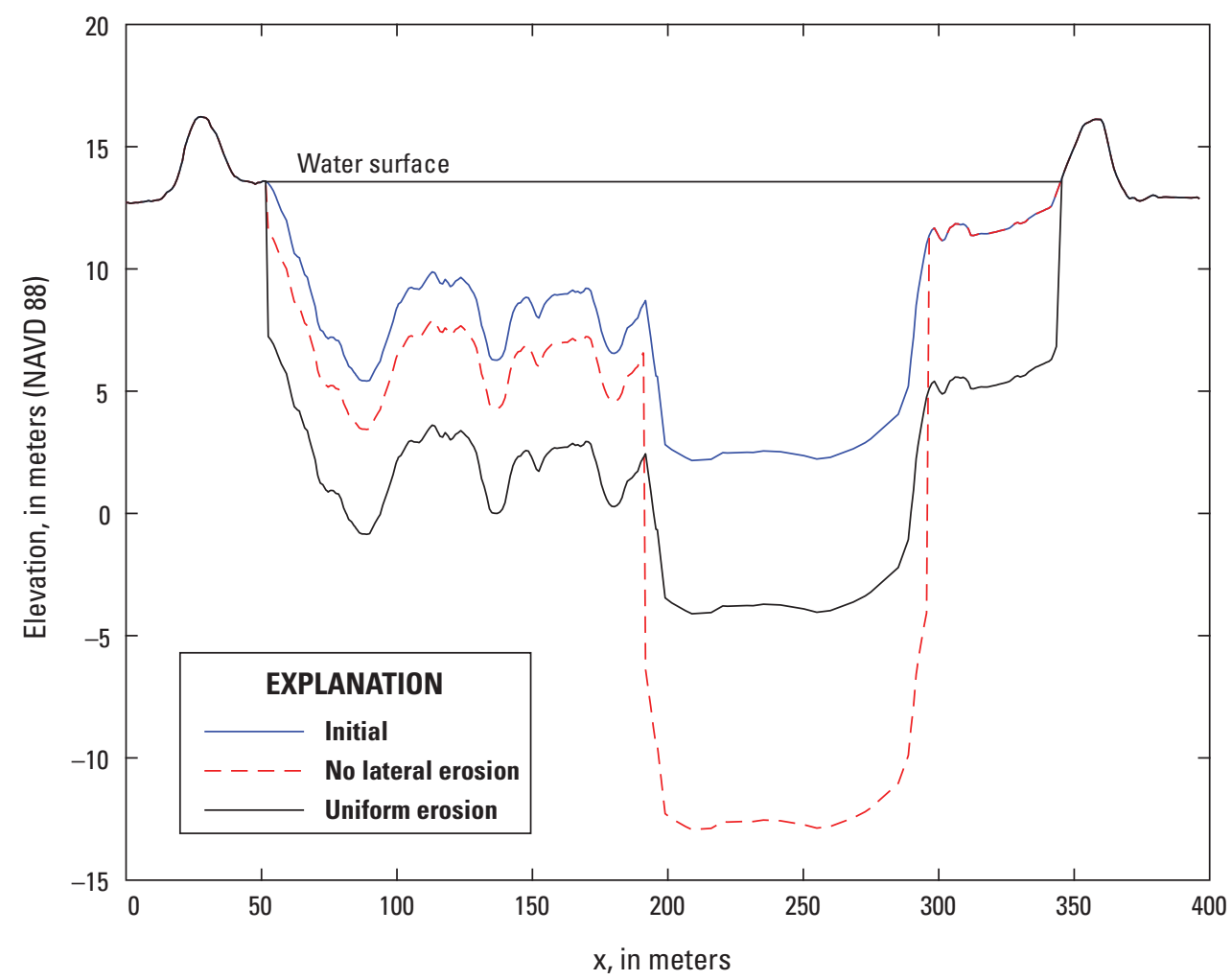

Figure 14. Model results of erosion caused by a simulated 200-year peak-flow event at station LAR4, lower American River, California. 
Some of the channel cross sections feature hard substrate and very strong lateral variations in the appearance of the surface sediments. Figure 15 is a photo taken from the Guy West Bridge (not shown) on the American River, approximately 1 kilometer $(\mathrm{km})$ downstream from station LAR6. Much of the channel that was visible underwater on the day of the photograph appears to be rock, riprap is lining the bank, and a variety of vegetation is present along the slope up to the levee. This lateral variability in erodibility is not included within the model.

If vertical erosion is precluded because of a hard substrate, the average depth does not change appreciably as the area increases. The channel would have to expand laterally to reach the equilibrium cross-sectional area. For the LAR4 cross section, the required expansion in width would be greater than the distance between the levee crests. This is an extreme example, however, dependent on the assumption that erodibility does not vary either horizontally or vertically above the hard substrate. Given data describing variability in sediment erodibility at a given cross section, spatial variations in erodibility could be included to improve model realism.

Table 5 shows the time required to reach equilibrium and the change in cross-sectional area that has resulted at the end of the model simulation. Given the assumptions and simplicity of the model, the numbers should not be taken in an absolute sense, but instead may be useful as an indication of which cross sections are more likely to exhibit large changes in cross-sectional area in the design peak-flow event. For example, results for the five upstream stations on the American River all indicate large increases in cross-sectional area, and much less change at the last three stations shown in table 5. Three of the stations on the American River had not reached equilibrium after 120 hours of simulation time.

When reviewing model results, it is important to recall the various model assumptions, and to recognize the sensitivity of the model to the various input parameters, and the uncertainty in those parameters. In the case of the new model applied here, empirically determined critical shear stress and erosion coefficients are unique to each cross section, contain substantial uncertainty, and strongly influence model results. The sensitivity of the model to critical shear stress and erosion coefficients was investigated by changing values systematically.

The critical shear stress plays a strong role in defining the equilibrium cross section and, subsequently, the area eroded during the evolution as well. The erosion coefficient, $k$, controls the erosion rate and the time required to reach equilibrium.

Figure 16 shows computed equilibrium cross sections for four different cases at station SAC3. All parameters were held constant for each case, except for critical shear stress, which was chosen to be $80,90,100,110$, and 120 percent of the best-fit value of 11.6 Pa for this cross section. When critical shear stress was set to 110 percent or more of the critical shear stress, erosion did not occur. Thus, the line showing the 110 percent result lies on top of the initial condition line.

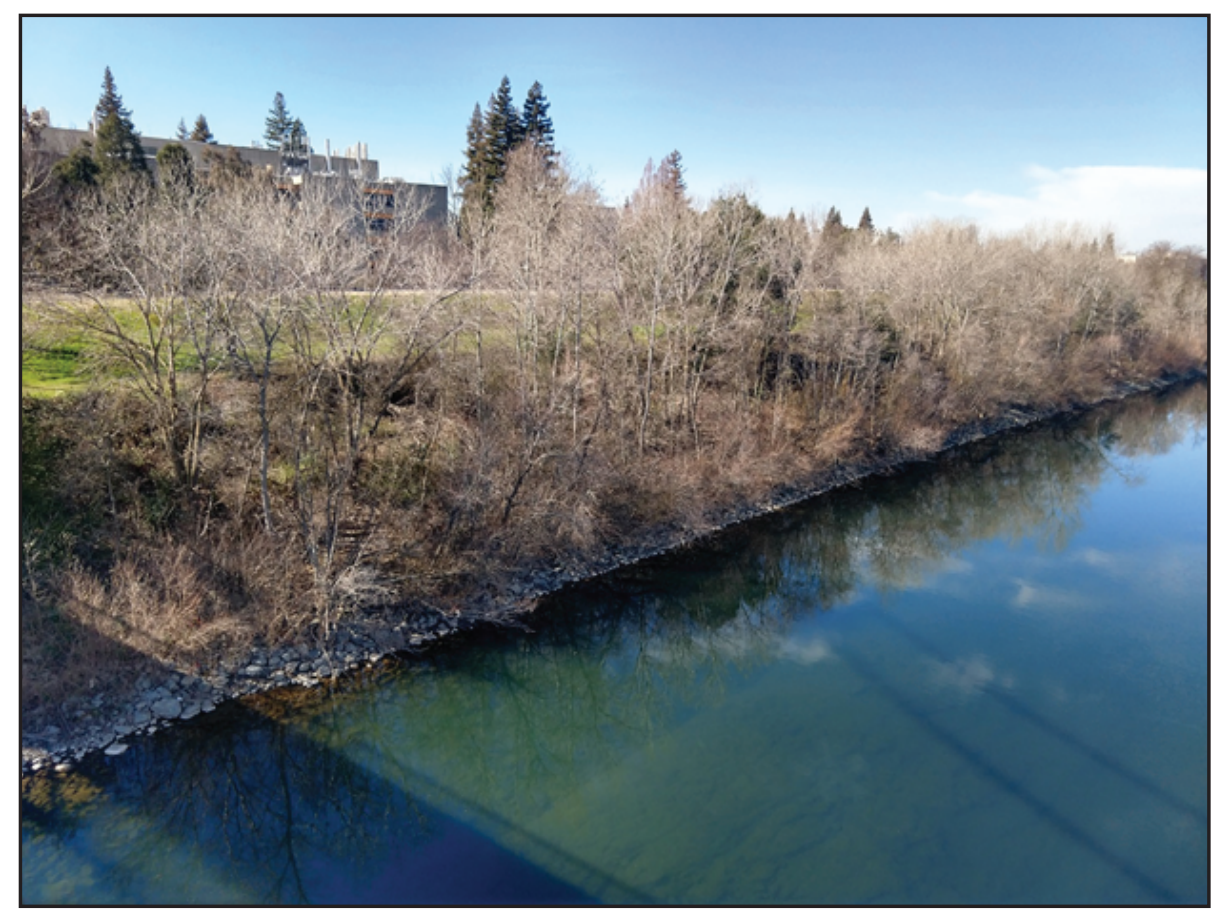

Figure 15. View of the left bank of the lower American River, looking downstream from the Guy West Bridge, Sacramento, California, on February 5, 2020. Photograph by Paul Work, U.S. Geological Survey. 
Table 5. Model results showing changes in cross-sectional areas caused by erosion from a 200-year peak-flow event at selected locations on the lower American and Sacramento Rivers, California.

[hrs, hours; $\mathrm{m}^{2}$, square meter; $>$, greater than]

\begin{tabular}{cccc}
\hline Station name & Time to equilibrium $(\mathbf{h r s})$ & Area change $\left(\mathbf{m}^{\mathbf{2}}\right)$ & Area change (percent) \\
\hline LAR1 & 91 & 2,080 & 124 \\
LAR2 & $>120$ & 3,920 & 233 \\
LAR4 & $>120$ & 1,840 & 98 \\
LAR5 & 32 & 3,050 & 214 \\
LAR8 & $>120$ & 2,740 & 215 \\
LAR9 & 19 & 180 & 7 \\
SAC3 & 18 & 113 & 5 \\
SAC7 & 0 & 0 & 0 \\
\hline
\end{tabular}

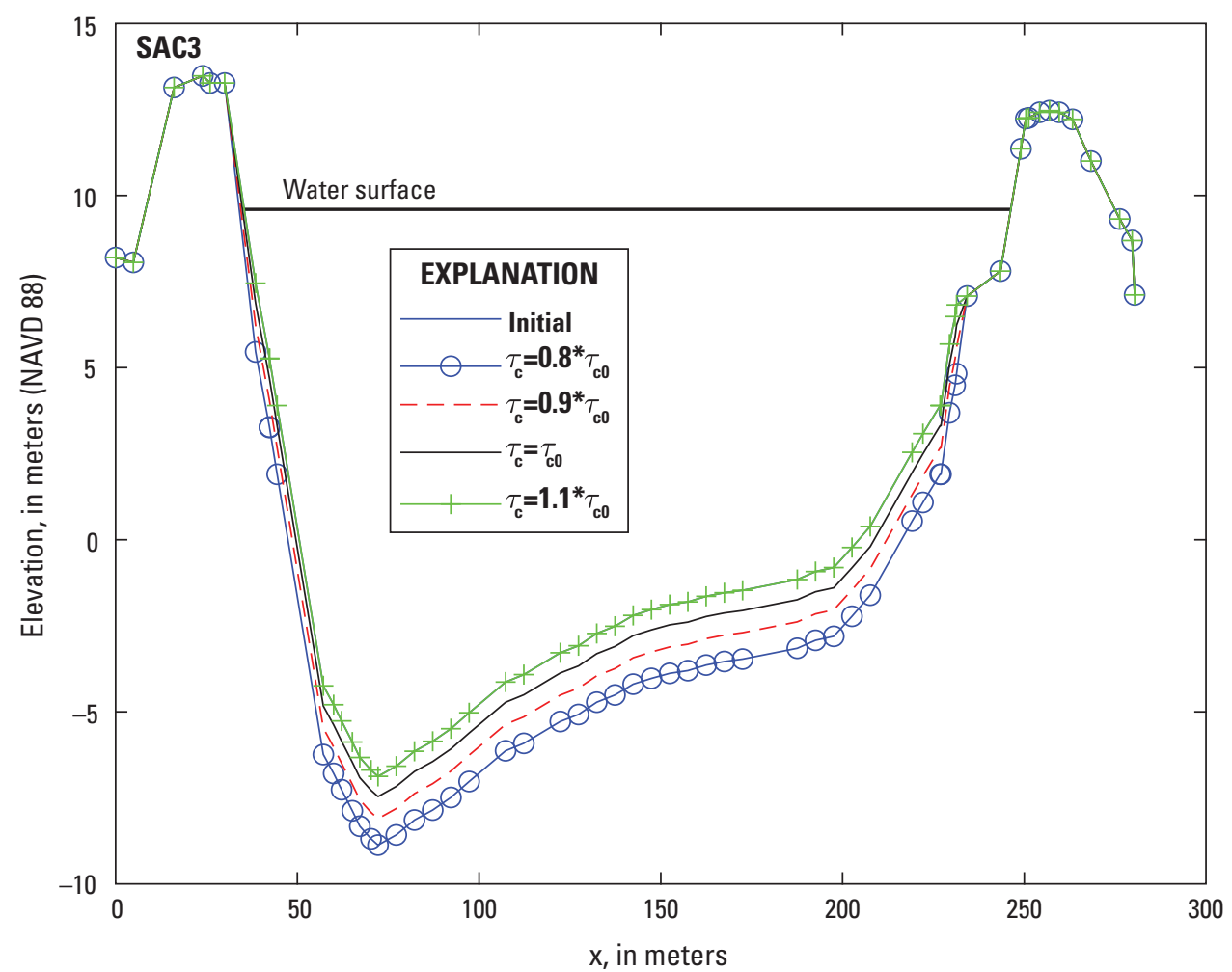

Figure 16. Sensitivity of equilibrium cross section for 200-year peak-flow event at station SAC3 on the Sacramento River, California, to specified critical shear stress, $\tau_{c}$. $\tau_{c 0}$ refers to the best-fit value of $\tau_{c}$ from erodibility tests. Last result shown in legend shows no erosion and thus falls on top of line showing initial condition. 
The result for 120 percent would likewise be zero erosion, so it was not plotted. The 100 percent case is shown by the solid black line. When the critical shear stress was reduced below this value, larger erosion rates resulted, and more of the cross section had to be eroded before the applied shear stress decreased below the critical value in each zone. Time to equilibrium ranged from none (110 and 120 percent cases) to 33 hours (80 percent case).

Results are not shown for different values of the erodibility coefficient $k$, because its primary influence is on the time required to reach equilibrium. Increasing or decreasing $k$ by 20 percent resulted in times to equilibrium ranging from 17 to 20 hours at station SAC3.

Another important parameter influencing the model results was the roughness of each of the three zones in each cross section of the model. The coefficient $\alpha$ in equation 11 represents the ratio of applied shear stress to the square of velocity; therefore, $\alpha$ is primarily controlled by bed roughness, which is difficult to estimate accurately. Values for $\alpha$ could not be input directly into the HEC-RAS model, but Manning's $n$ values were adjusted to represent $\alpha$ values (Munson and others, 2013). In the new erosion model, $\alpha$ was computed as shear stress divided by the square of velocity. Resulting values of $\alpha$ for each of the three zones were kept constant for the entire simulation.

Increasing or decreasing the value of $\alpha$ in each zone by 10 or 20 percent resulted in erosion profiles shown in figure 17 . The symbol $\alpha_{0}$ designates the value computed by the model, which is unique to each flow zone. Results for $\alpha$ that are 10 percent and 20 percent less than $\alpha_{0}$ are not shown because erosion did not occur - the applied bed shear stress in each zone was less than the critical shear stress needed to initiate erosion. When $\alpha$ is increased by 10 percent and then 20 percent, shear stress on the bed was increased for any given flow speed, and the area eroded to reach equilibrium increased. Model sensitivities to bed roughness and critical shear stress are similar - the difference between the applied and critical values of the shear stress regulated model behavior.

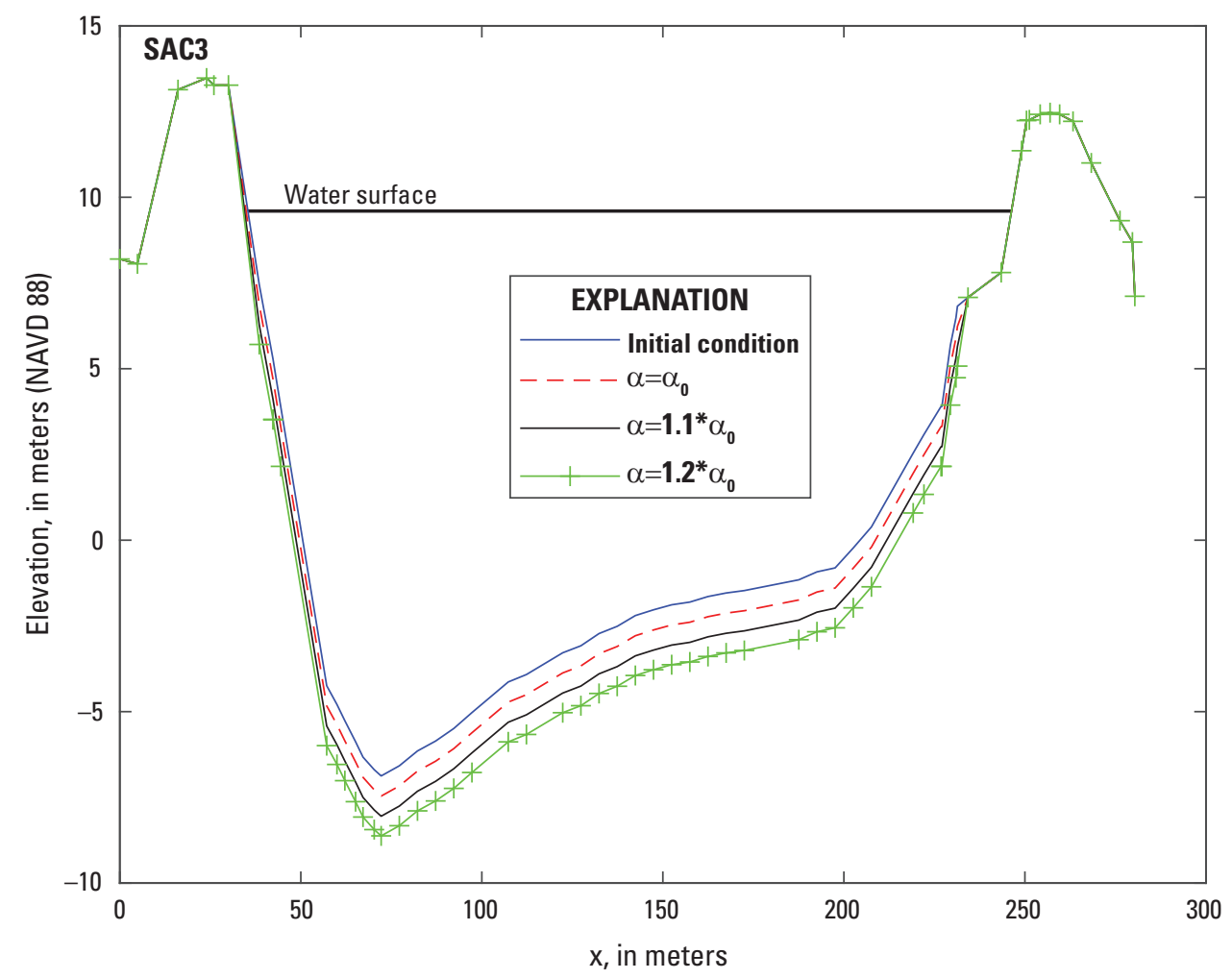

Figure 17. Model sensitivity of erosion estimate to bed-drag coefficient, represented by the coefficent $\alpha$ in $\tau=\alpha V^{2}$ (eq. 11), which solves for shear stress, $\tau$, relative to velocity, $V$. Subscript 0 denotes values derived from field measurements. 


\section{Summary and Conclusions}

The U.S. Geological Survey and the U.S. Army Corps of Engineers collaborated on a study to obtain data about the erodibility of sediments between levees on the American and Sacramento Rivers and compare erodibilities measured using three different methods. Three independent sets of tests were used to acquire relevant data. Undisturbed and reconstituted sediment samples were extracted from drilled boreholes and tested in an erosion function apparatus (EFA) in a laboratory at Texas A\&M University to estimate erosion rate as a function of flow speed and applied shear stress. Borehole erosion tests (BETs) were completed to measure erosion rates relative to flow speed and applied shear stress in an in situ approach. Erodibility results from EFA and BET methods were compared to erodibility results from a previous study by the U.S. Department of Agriculture (USDA). The USDA did a series of jet erosion tests (JETs) to assess the erodibility of surface sediments in the test area. The pros and cons and erodibility results from the EFA, BET, and JET approaches are discussed and compared in this report.

The EFA testing approach had two major pros. By subjecting sediment samples to a finely controlled flow speed in the laboratory, users could gradually approach and observe the onset of erosion to define the critical velocity for initiation of erosion. Critical velocities can be used to compute critical shear stress given suitable assumptions to determine a friction factor. The other major advantage is that the sediment sample can be subjected to many different flow speeds to improve resolution of the curve relating erosion rate to applied shear stress. A con of the EFA approach is that sediment samples must be extracted, potentially changing erodibility in the process.

Pros and cons of the BET are enumerated by Work and Livsey (2020) in a previous report that resulted from this study. The in situ approach of the BET produces results in one test for the entire drilled hole, except for the top and bottom regions. The BET, however, is logistically complicated and provides results for only a few shear stresses. Therefore, confidently determining a critical shear stress or slope of the erosion function is difficult. Typically, only a few different flow rates can be tested before the borehole enlarges to the point where flow speeds are reduced, after which more tests provide little additional useful information.

The differences between the results obtained by the EFA and BET approaches are described in this report. The EFA tests typically resulted in much higher erosion rates at much lower applied shear stresses than erosion rates measured using the BET for the same lithological layers. Differences in roughness and ways in which shear stresses were computed may explain some of the differences in applied shear stresses between the EFA and BET methods, but differences in roughness do not explain the large discrepancy in observed erosion rates or coefficients relating erosion rates to excess shear stress. Some of the EFA tests were done with sediment that had been disturbed and was reconsolidated in a tube for testing. This may have made the sediments more erodible.

The jet erosion test (JET) is an in situ test requiring less equipment than the BET. The JET provides erosion results for the bed surface that cannot be measured with the BET, but the JET cannot be used to test regions beneath the bed.

A new model was developed and applied to simulate erosion of surveyed cross sections of the American and Sacramento Rivers, identify cross sections that are most likely to demonstrate large changes in area during the design peakflow event, identify cross sections that reach equilibrium, and determine the timing of when cross sections reach equilibrium. The numerical model simulates the erosion of a cross section subjected to a high, constant flow. In the model, sediments are assumed to be homogeneous within the cross section, and the model does not account for slumping of bank sediments. Results were provided showing evolution of each cross section for which JETs were complete, using erosion function parameters derived from the JETs. Derived values of critical shear stress were larger for JETs compared to critical shear stress values derived using the BET and EFA. Sensitivities of the numerical model to critical shear stress, erosion coefficient, and bed roughness were demonstrated by varying each parameter up and down by up to 20 percent, but the differences between the values of these parameters derived from the BET, EFA, and JETs were more than 20 percent.

The data collected for this study represent a major undertaking by four different institutions, applying three different methods of obtaining data to quantify erodibility of riverbed sediments, either in situ or with laboratory testing. Each of the three methods has advantages and disadvantages, and they do not all provide the same information. Erodibility results are wide-ranging, with large differences among erosion rates obtained at the same nominal locations using different methods and large differences between repeated tests. Given these differences, it is important to have several sets of results in hand for comparison. The EFA test produced the highest values of the coefficient in the erosion function that controls the rate of erosion, and the JETs produced the greatest values of critical shear stress, which controls when erosion is initiated. The BET reached higher values of applied shear stress than the EFA but produced lower erosion rates. Together, the tests provide bounds on the range of erosion rates likely to be found in the study area and on their associated spatial variability.

The developed numerical model was used to indicate the regions likely to show the most change in the design peak-flow event. Model simulations demonstrated that large increases in cross-sectional area occurred in the American River during the design peak-flow event. In contrast, the two Sacramento River cross sections considered were at or close to equilibrium size before the start of the design peak-flow event. 


\section{References Cited}

Borrowman, T.D., Smith, E.R., Gailani, J.Z., and Caviness, L., 2006, Erodibility study of Passaic River sediments using USACE Sedflume: Vicksburg, Miss., U.S. Army Engineer Research and Development Center, 44 p., https://doi.org/doi:10.7282/T38W3DB4.

Briaud, J.-L., Ting, F.C.K., Chen, H.C., Cao, Y., Han, S.W., and Kwak, K.W., 2001, Erosion function apparatus for scour predictions: Journal of Geotechnical and Geoenvironmental Engineering, v. 127, no. 2, p. 105-113, https://doi.org/10.1061/(ASCE)1090-0241(2001)127:2(105).

Briaud, J.-L., Chedid, M., Chen, H.-C., and Shidlovskaya, A., 2017, Borehole erosion test: Journal of Geotechnical and Geoenvironmental Engineering, American Society of Civil Engineers, v. 143, no. 8, 12 p., https://doi.org/10.1061/ (ASCE)GT.1943-5606.0001712.

Briaud, J.-L., Shidlovskaya, A., and Timchenko, A., 2020, Assessing erosion resistance of bank materials on American and Sacramento Rivers: Texas A\&M University, April 2020, 70 p.

Daly, E.R., Fox, G.A., and Miller, R.B., 2013, A scour depth approach for deriving erodibility parameters from jet erosion tests: Transactions of the ASABE, v. 56, no. 6, p. 1343-1351, https://doi.org/10.13031/trans.56.10350.

Hanson, G.J., 1991, Development of a jet index to characterize erosion resistance of soils in earthen spillways: Transactions of the ASABE, v. 34, no. 5, p. 2015-2020, https://doi.org/ $10.13031 / 2013.31831$.

Hanson, G.J., and Cook, K.R., 2004, Apparatus, test procedures, and analytical methods to measure soil erodibility in situ: Applied Engineering in Agriculture, v. 20, no. 4, p. 455-462, https://doi.org/10.13031/2013.16492.

Hanson, G.J., and Simon, A., 2001, Erodibility of cohesive streambeds in the loess area of the midwestern USA: Journal of Hydrological Processes, v. 15, no. 1, p. 23-38, https://doi.org/10.1002/hyp.149.

Jepsen, R.A., 2006, Uncertainty in experimental techniques for measuring sediment erodibility: Integrated Environmental Assessment and Management, v. 2, no. 1, p. 39-43, https://doi.org/10.1002/ieam.5630020108.

Jones, C., and Gailani, J., 2009, Discussion of "Comparison of two techniques to measure sediment erodibility in the Fox River, Wisconsin" by T. Ravens: Hydraulic Engineering, v. 135, no. 5, p. 432-434, https://doi.org/10.1061/ (ASCE)HY.1943-7900.0000002.
Khanal, A., Fox, G.A., and Al-Madhhachi, A.T., 2016, Variability of erodibility parameters from laboratory mini jet erosion tests: Journal of Hydrolic Engineering, American Society of Civil Engineers, v. 21, no. 10, 17 p., https://doi.org/10.1061/(ASCE)HE.1943-5584.0001404.

Klavon, K., Fox, G.A., Guertault, L., Langendoen, E.J., Enlow, H., Miller, R.B., and Khanal, A., 2017, Evaluating a process-based model for use in streambank stabilizationInsights on the bank stability and toe erosion model (BSTEM): Earth Surface Processes and Landforms, v. 42, no. 1, p. 191-213, https://doi.org/10.1002/esp.4073.

Langendoen, E.J., and Ursic, M.E., 2020, Erodibility of bank materials on the lower American and Sacramento rivers, adjacent to the city of Sacramento, California: Research Report No. 80, April 15, 2020, U.S. Deptartment of Agriculture, ARS, National Sedimentation Laboratory, Oxford, Miss, $121 \mathrm{p}$.

Lyons, W.C., and Plisga, G.J., 1996, Standard handbook of petroleum and natural gas engineers: Houston, Texas, Gulf Professional Publishing, $1077 \mathrm{p}$.

Maa, J.P.-Y., Wright, L.D., Lee, C.-H., and Shannon, T.W., 1993, VIMS sea carousel - A field instrument for studying sediment transport: Marine Geology, v. 115, no. 3-4, p. 271-287, https://doi.org/10.1016/0025-3227(93)90056-2.

McNeil, J., Taylor, C., and Lick, W., 1996, Measurements of erosion of undisturbed bottom sediments with depth: Journal of Hydraulic Engineering, v. 122, no. 6, p. 316-324, https://doi.org/10.1061/(ASCE)07339429(1996)122:6(316).

Munson, B.R., Okiishi, T.H., Huebsch, W.W., and Rothmayer, A.P., 2013, Fundamentals of fluid mechanics (7th ed.): Hoboken, New Jersey, Wiley, 792 p.

National Academies of Sciences, Engineering, and Medicine, 2004, Pier and contraction scour in cohesive soils: Washington, DC, The National Academies Press, 125 p., https://doi.org/10.17226/13774.

Ravens, T.M., 2007, Comparison of two techniques to measure sediment erodibility in the Fox River, Wisconsin: Journal of Hydraulic Engineering, v. 133, no. 1, p. 111-115, https://doi.org/10.1061/(ASCE)07339429(2007)133:1(111).

Roberts, J.D., Jepsen, R.A., and James, S.C., 2003, Measurements of sediment erosion and transport with the adjustable shear stress erosion and transport flume: Journal of Hydraulic Engineering, v. 129, no. 11, p. 862-871, https://doi.org/10.1061/(ASCE)0733-9429(2003)1 29:11(862). 
Simon, A., Curini, A., Darby, S.E., and Langendoen, E.J., 2000, Bank and near-bank processes in an incised channel: Geomorphology, v. 35, no. 3-4, p. 193-217, https://doi.org/ $10.1016 / \mathrm{S} 0169-555 \mathrm{X}(00) 00036-2$.

Simon, A., Thomas, R.E., and Klimetz, L., 2010, Comparison and experiences with field techniques to measure critical shear stress and erodibility of cohesive deposits: Las Vegas, Nev., 2nd Joint Federal Interagency Conference, p. 1-13, https://acwi.gov/sos/pubs/2ndJFIC/Contents/5A2_Simon_ 3_9_2010_paper.pdf.

Simon, A., Pollen-Bankhead, N., and Thomas, R.E., 2011, Development and application of a deterministic bank stability and toe erosion model for stream restorationStream restoration in dynamic fluvial systems, in Simon, A., Bennett, S.J., and Castro, J.M., eds., Stream restoration in dynamic fluvial systems - Scientific approaches, analyses, and tools v. 194: Washington, DC, American Geophysical Union, p. 453-474, https://doi.org/10.1029/ 2010 GM001006.

Tolhurst, T.J., Black, K.S., Paterson, D.M., Mitchener, H.J., Termaat, G.R., and Shayler, S.A., 2000, A comparison and measurement standardisation of four in situ devices for determining the erosion shear stress of intertidal sediments: Continental Shelf Research, v. 20, no. 10-11, p. 1397-1418, https://doi.org/10.1016/S0278-4343(00)00029-7.

Trammel, M.A., 2004, Laboratory apparatus and methodology for determining water erosion rates of erodible rock and cohesive sediments: Gainesville, Flo., University of Florida, M.S. thesis, $135 \mathrm{p}$.

Tran, T.V., 2018, Instrumentation of erosion function apparatus and evaluation of a new erosion characterization methodology: Manhattan, Kan., Kansas State University, Ph.D. dissertation.
U.S. Army Corps of Engineers, 2016, HEC-RAS River analysis system-Users manual v. 5.0, February 2016: Davis, Calif., U.S. Army Corps of Engineers, Hydrologic Engineering Center, 960 p.

U.S. Geological Survey, 2021, National Water Information System: U.S. Geological Survey Web interface, https://doi.org/10.5066/F7P55KJN.

Van Prooijen, B.C., and Winterwerp, J.C., 2010, A stochastic formulation for erosion of cohesive sediments: Journal of Geophysical Research. Oceans, v. 115, no. C1, 15 p., https://doi.org/10.1029/2008JC005189.

Widdows, J., Friend, P.L., Bale, A.J., Brinsley, M.D., Pope, N.D., and Thompson, C.E.L., 2007, Inter-comparison between five devices for determining erodability (sic) of intertidal sediments: Continental Shelf Research, v. 27, no. 8, p. 1174-1189, https://doi.org/10.1016/ j.csr.2005.10.006.

Work, P.A., and Livsey, D., 2020, Sediment lithology and borehole erosion testing, American and Sacramento Rivers, California: U.S. Geological Survey Scientific Investigations Report 2020-5063, 92 p., https://doi.org/10.3133/ $\operatorname{sir} 20205063$.

Work, P.A., and Livsey, D., 2021, Borehole Erosion Test data, Lower American and Sacramento Rivers, California, 2019 (ver. 4.0, 2021), https://doi.org/10.5066/P96MCT2Q.

Work, P.A., and Schoellhamer, D.H., 2018, Measurements of erosion potential using Gust chamber in Yolo Bypass near Sacramento, California: U.S. Geological Survey OpenFile Report 2018-1062, 17 p., https://doi.org/10.3133/ ofr20181062.

Yang, C.T., 1996, Sediment transport theory and practice: New York, NY, McGraw-Hill Companies Inc, 412 p. 


\section{Appendix 1. Plots Relating Erosion and Shear Stress Data Derived from Borehole Erosion Tests for the American and Sacramento Rivers}

Each of the plots in this section shows Borehole erosion test results at a specific location on the American or Sacramento Rivers. Site locations are shown in figures 1 and 2.

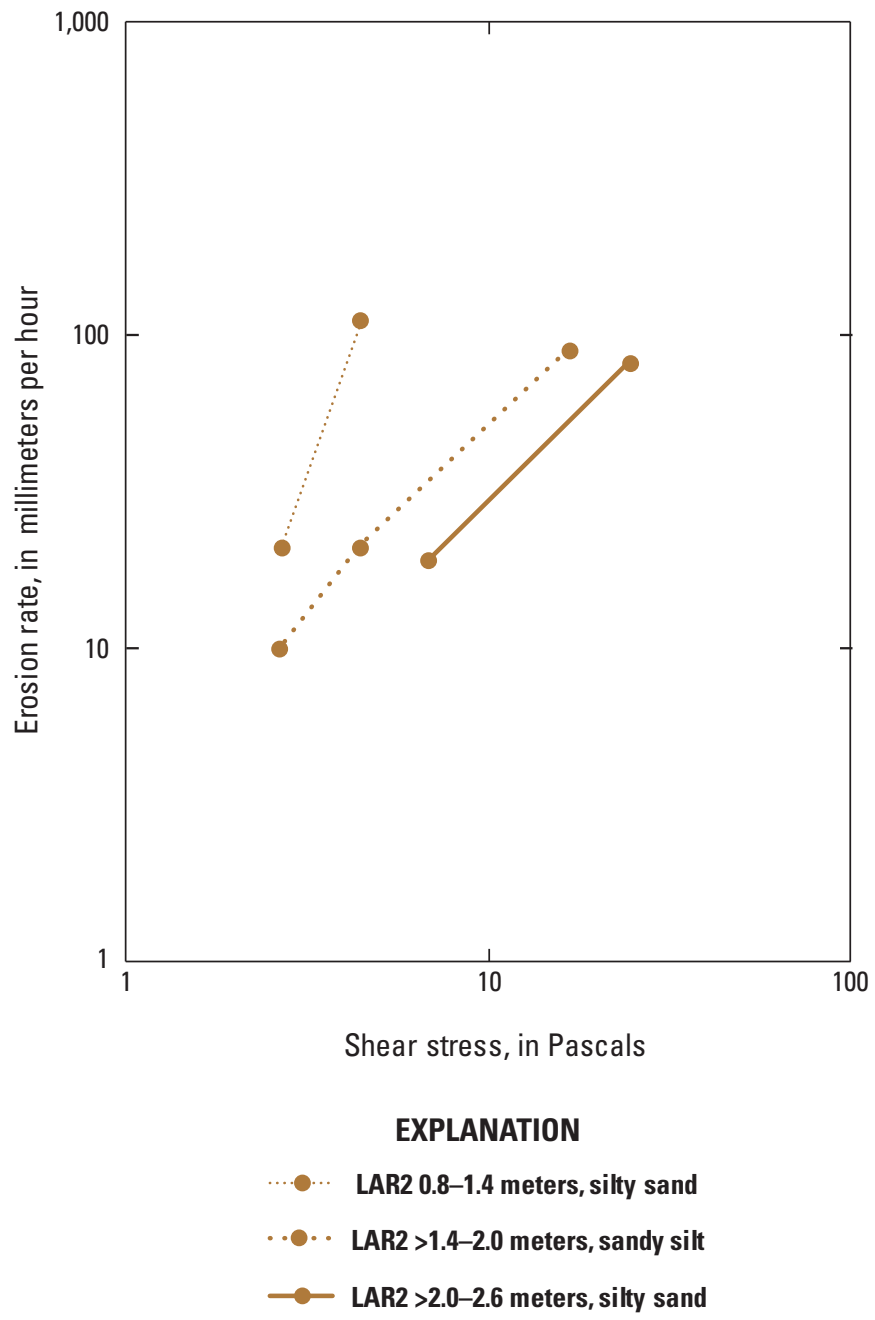

Figure 1.1. Borehole erosion test results at site LAR2 on the lower American River, Calif.

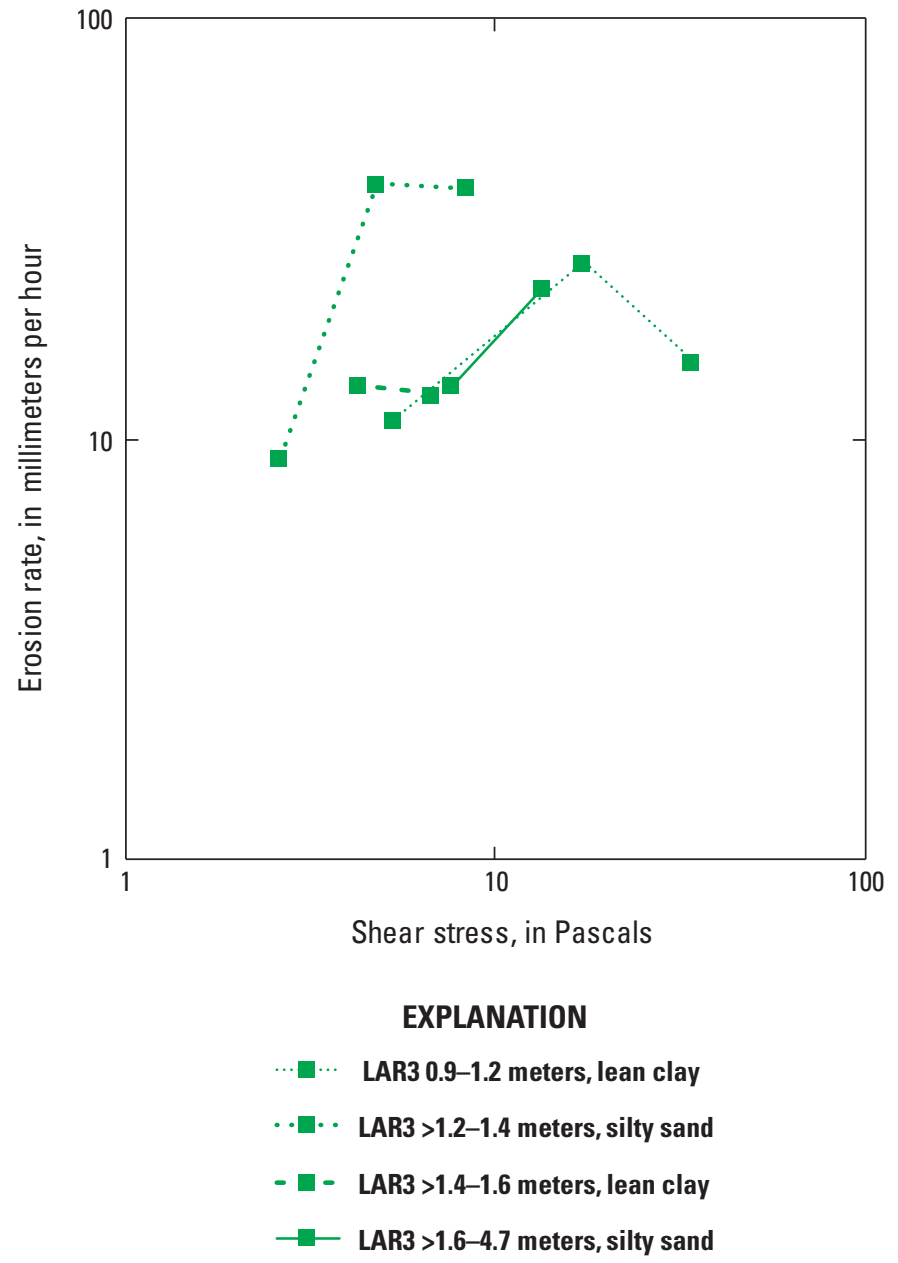

Figure 1.2. Borehole erosion test results at site LAR3 on the lower American River, Calif. 


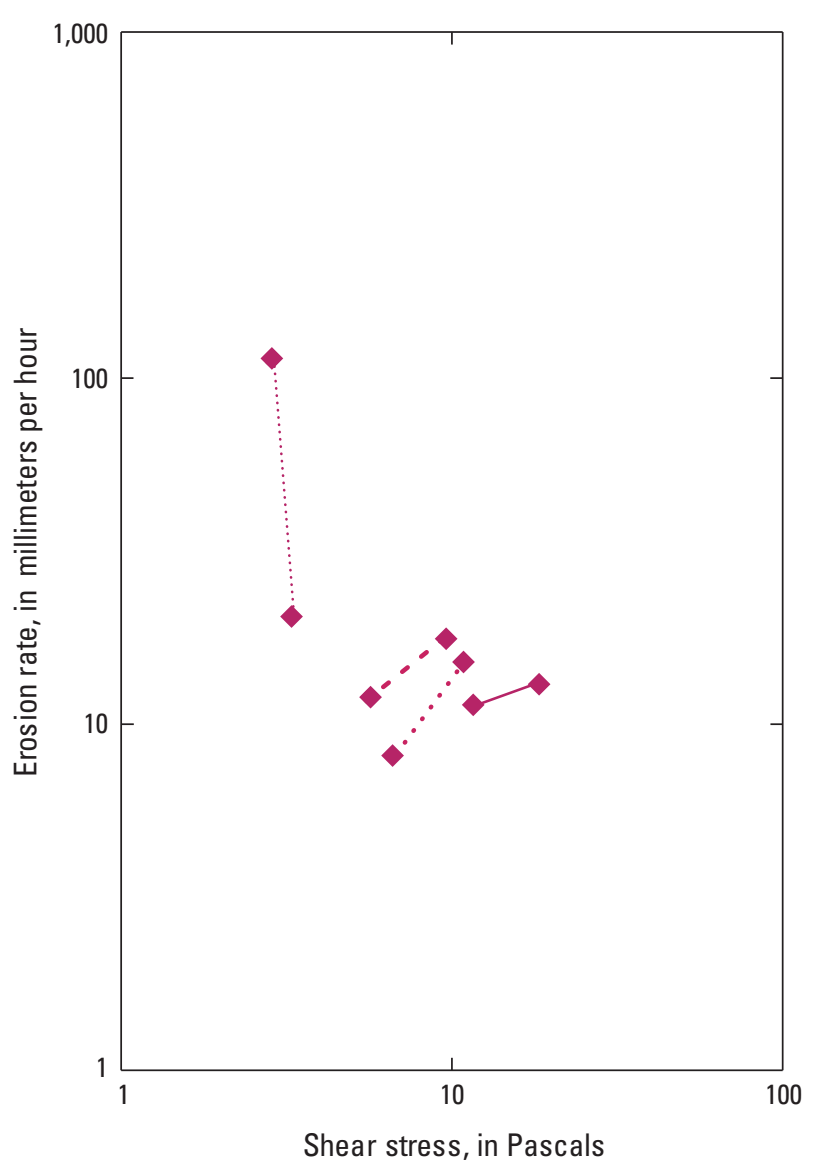

\section{EXPLANATION}

$\cdots \quad$ LAR5 0.8-1.5 meters, clayey sand

- $\triangleleft$. LAR5 >1.5-2.1 meters, poorly graded sand with silt

- - LAR5 >2.1-2.7 meters, silty sand

$\longrightarrow$ LAR5 > 2.7-3.4 meters, poorly graded sand with silt

Figure 1.3. Borehole erosion test results at site LAR5 on the lower American River, Calif.

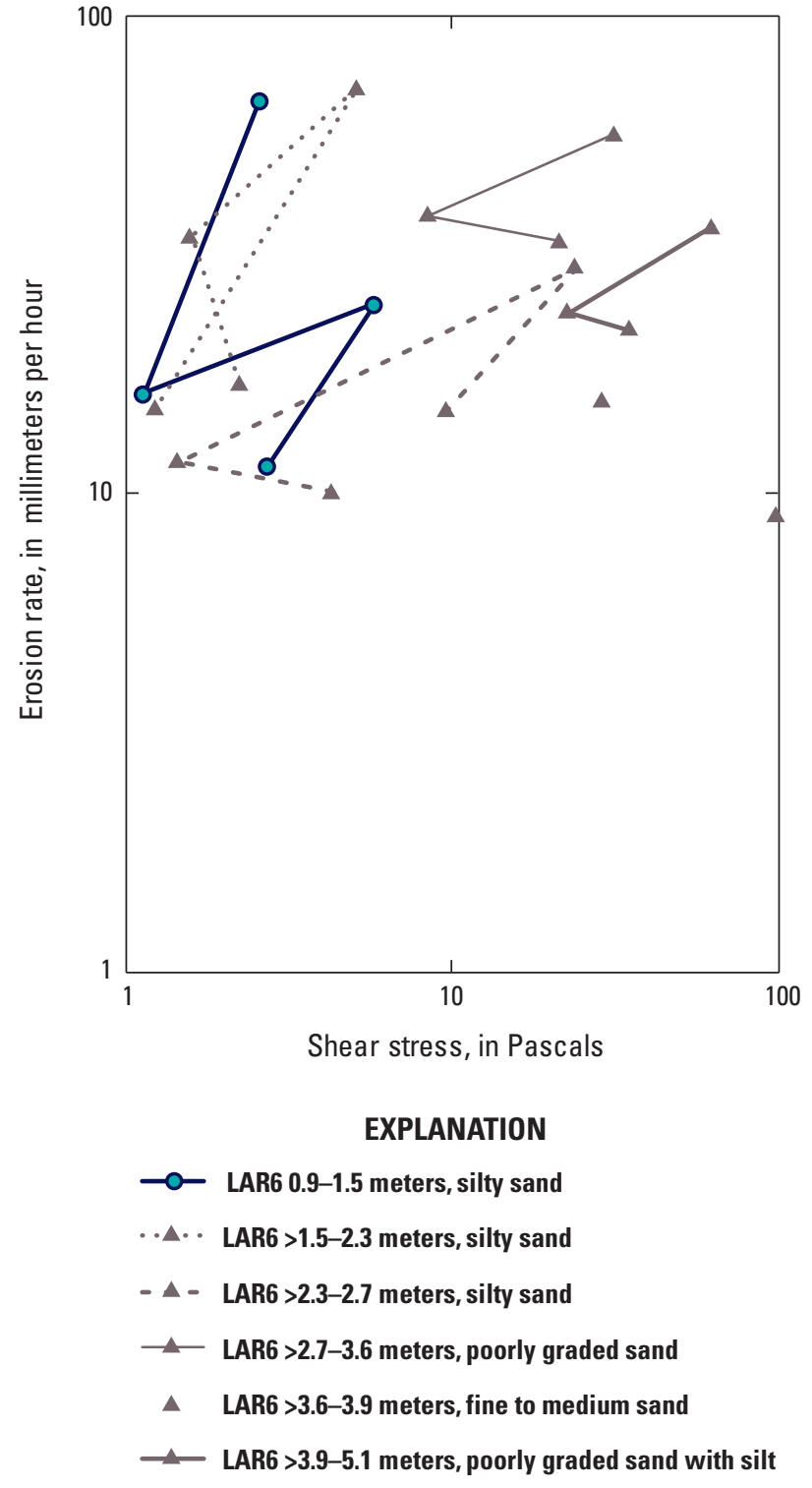

Figure 1.4. Borehole erosion test results at site LAR6 on the lower American River, Calif. 


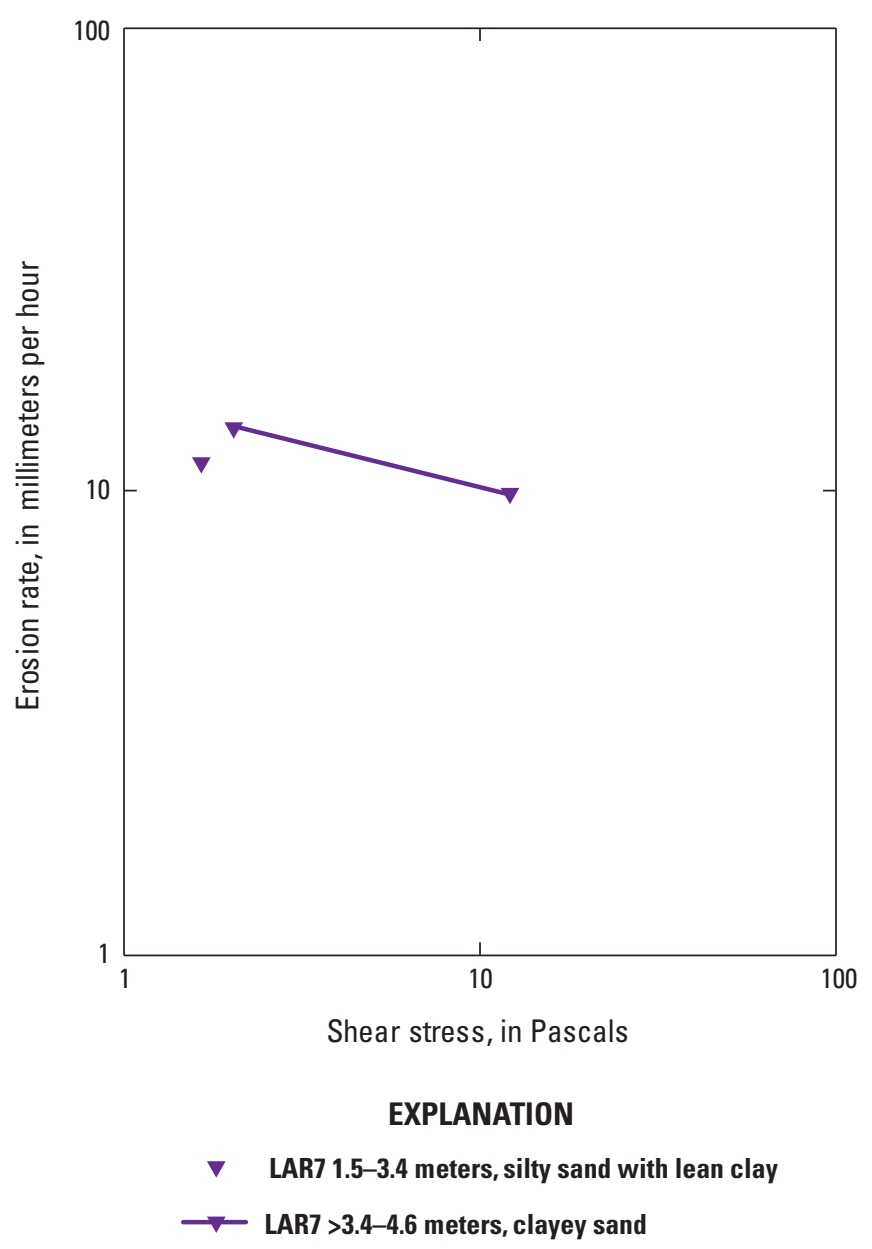

Figure 1.5. Borehole erosion test results at site LAR7 on the lower American River, Calif.

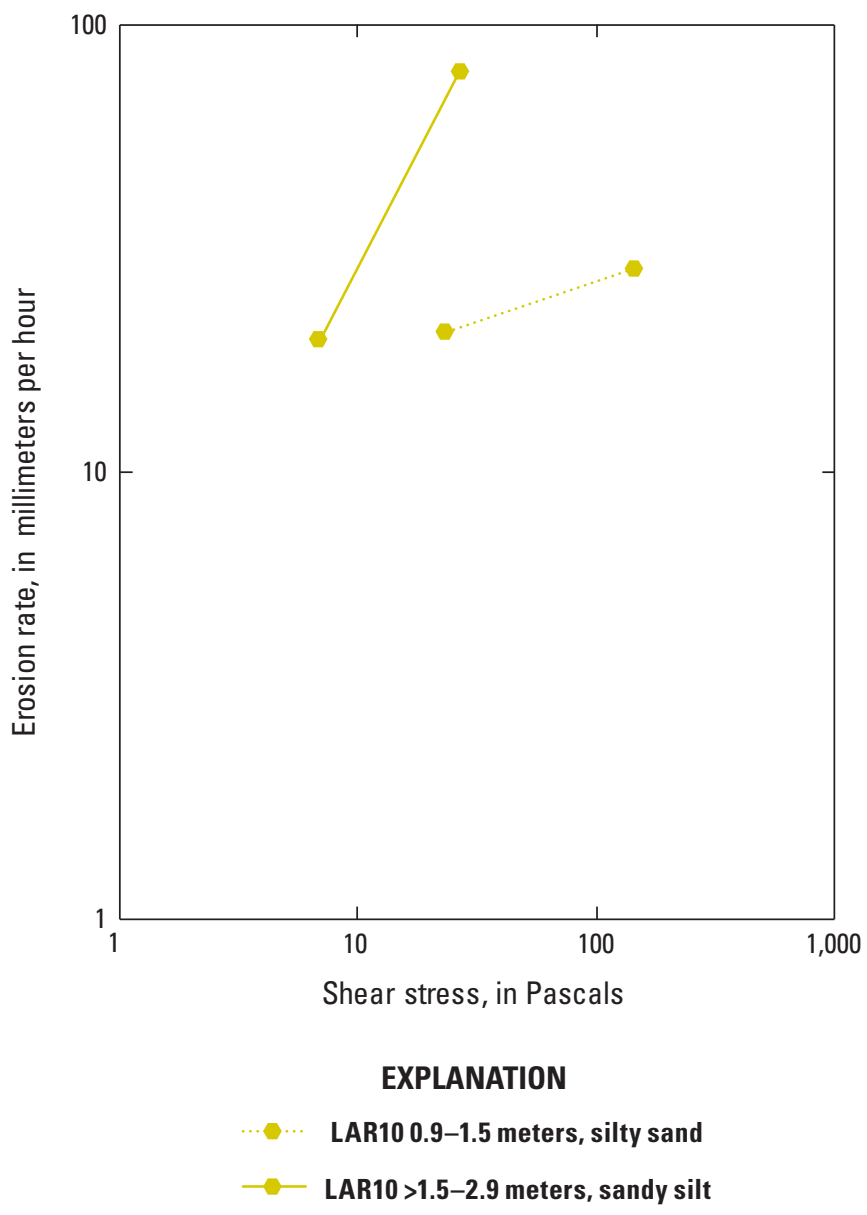

Figure 1.6. Borehole erosion test results at site LAR10 on the lower American River, Calif. 


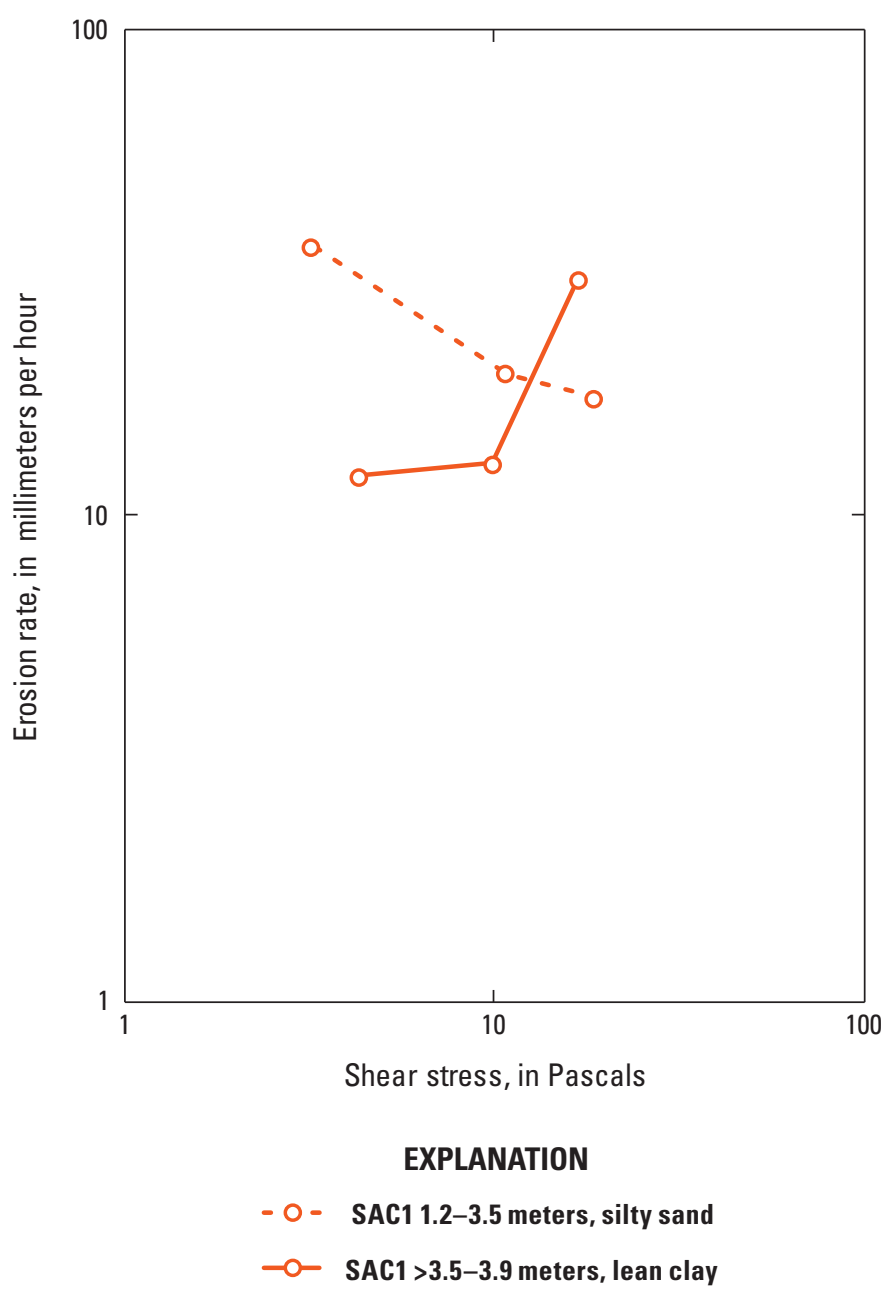

Figure 1.7. Borehole erosion test results at site SAC1 on the Sacramento River, Calif.

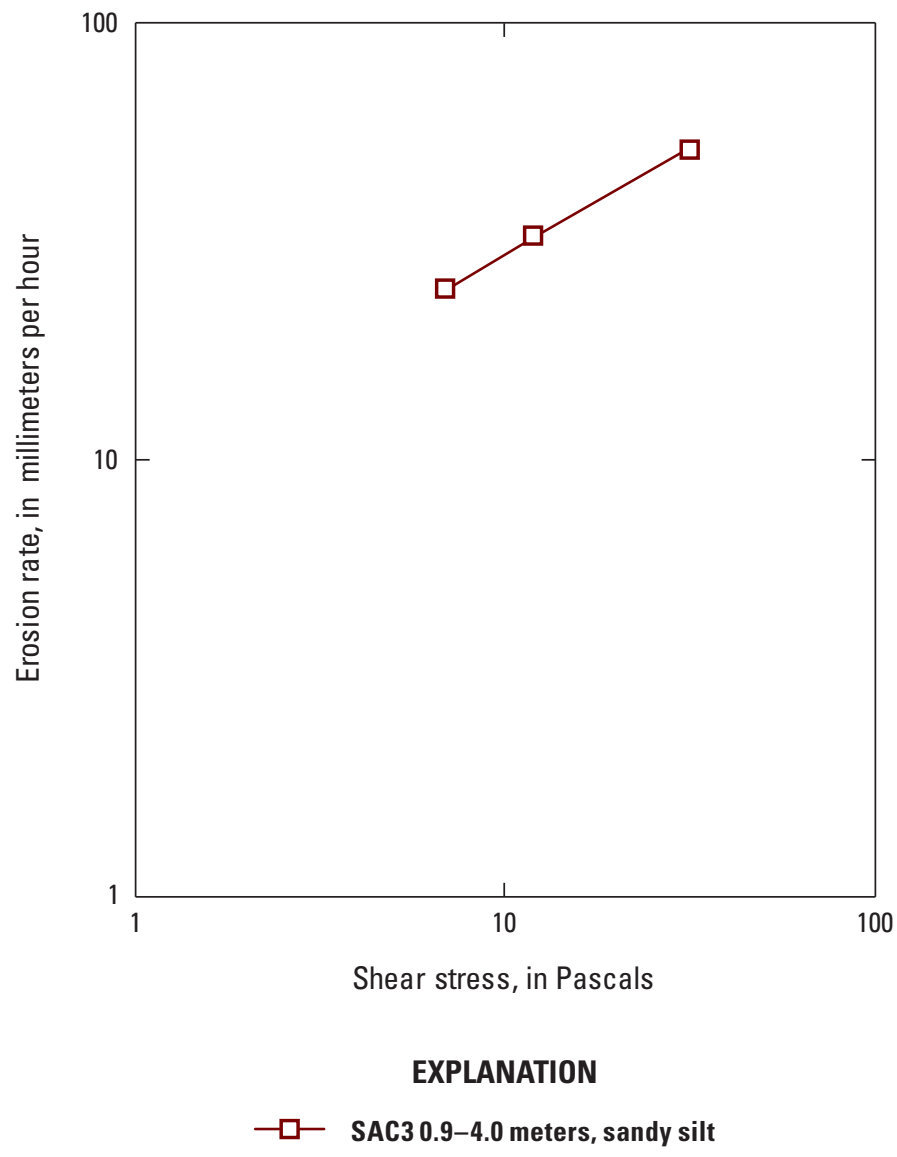

Figure 1.8. Borehole erosion test results at site SAC3 on the Sacramento River, Calif. 


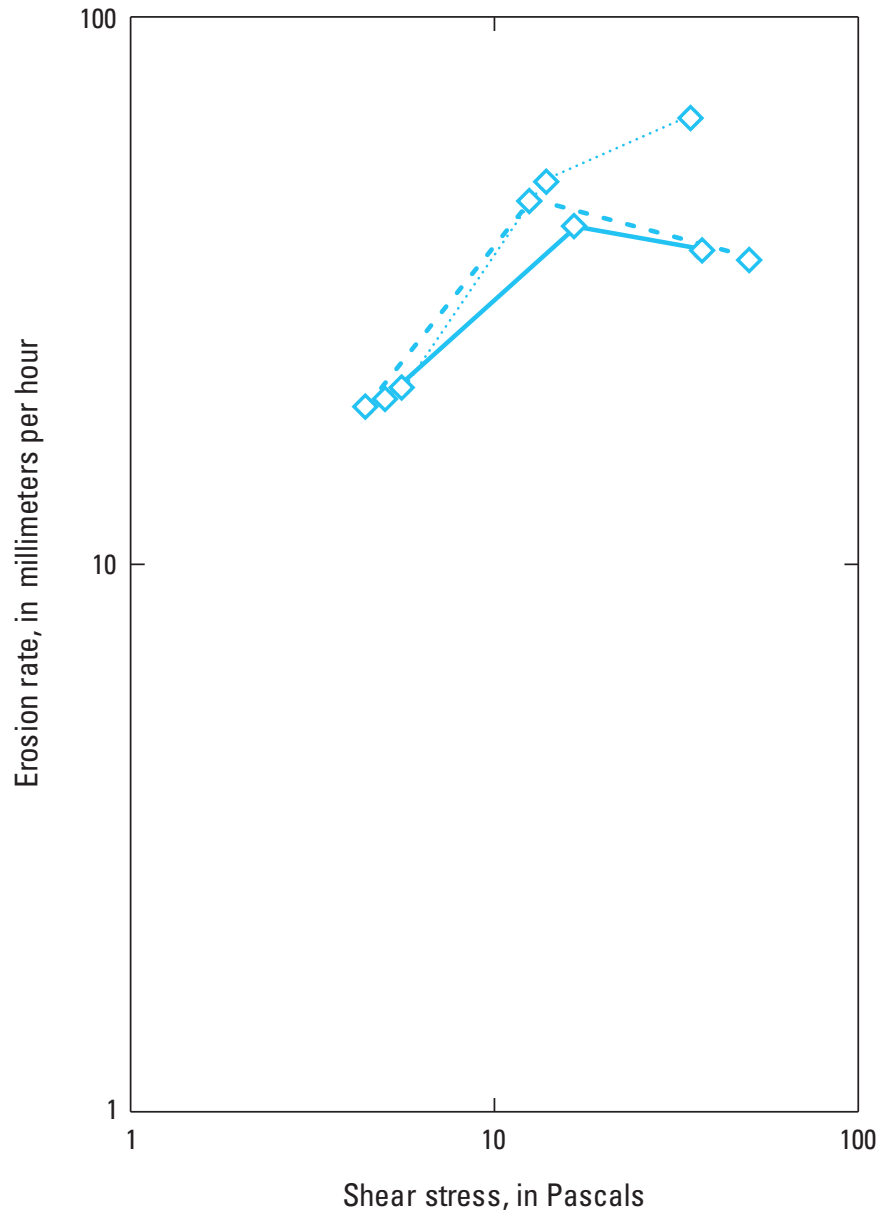

\section{EXPLANATION}

$\triangle \cdots$ SAC7 0.9-2.6 meters, silt with sand

$-\diamond-$ SAC7 $>2.6-3.0$ meters, sandy lean clay

$\checkmark$ SAC7 >3.0-4.6 meters, silt with sand

Figure 1.9. Borehole erosion test results at site SAC7 on the Sacramento River, Calif.

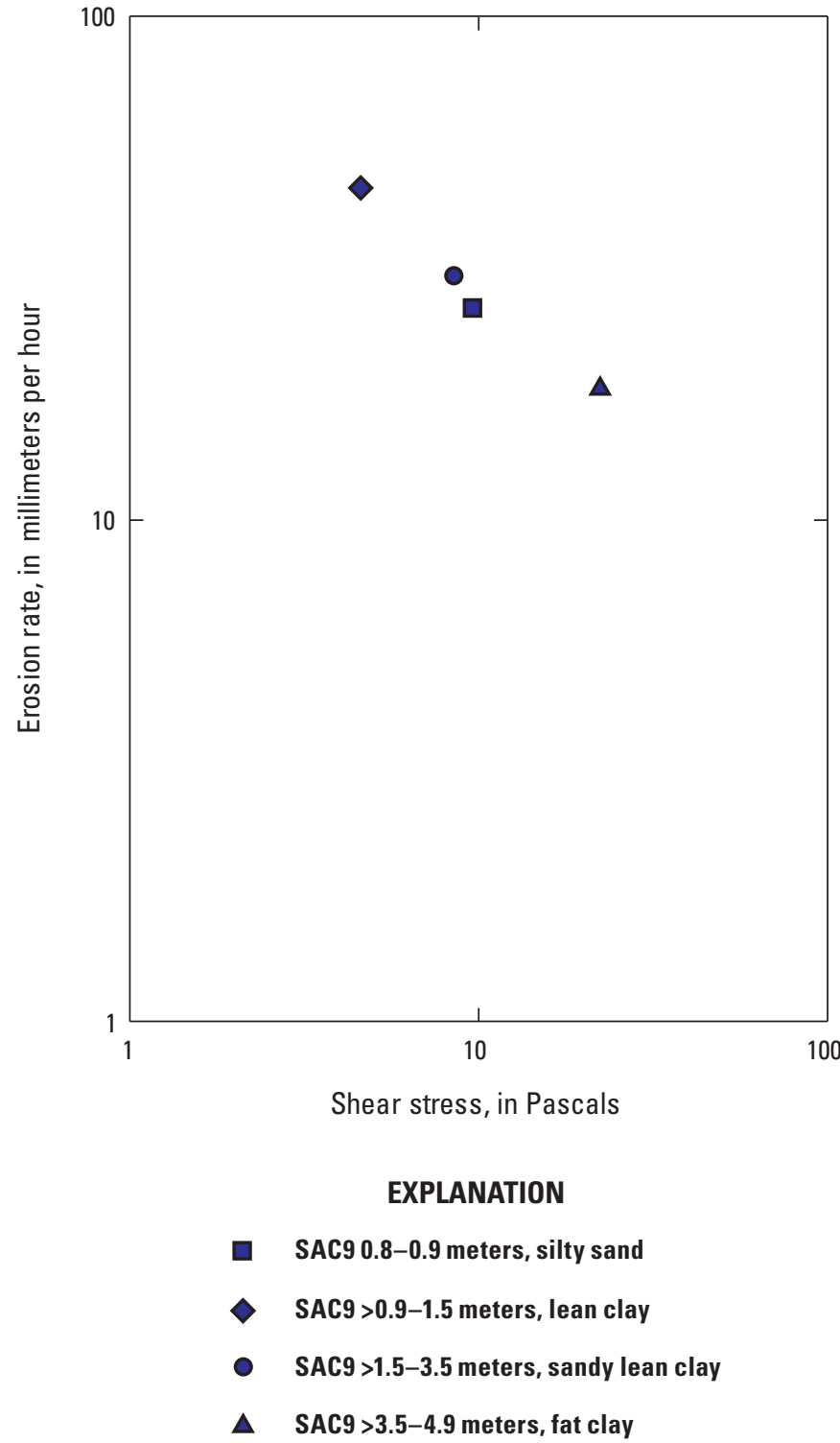

Figure 1.10. Borehole erosion test results at site SAC9 on the Sacramento River, Calif. 
For more information concerning the research in this report, contact the

Director, California Water Science Center

U.S. Geological Survey

6000 J Street, Placer Hall

Sacramento, California 95819

https://ca.water.usgs.gov

Publishing support provided by the U.S. Geological Survey Science Publishing Network, Sacramento Publishing Service Center 


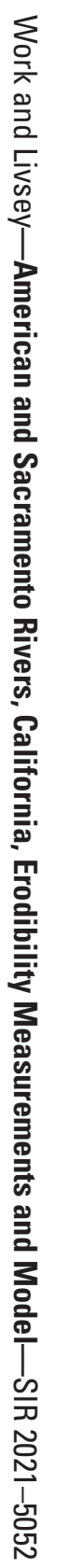

